\title{
Encouraging testicular self-examination behaviors in college males: Examining the role of fear appeals in protection motivation theory
}

\author{
Cara L. Slider \\ West Virginia University
}

Follow this and additional works at: https://researchrepository.wvu.edu/etd

\section{Recommended Citation}

Slider, Cara L., "Encouraging testicular self-examination behaviors in college males: Examining the role of fear appeals in protection motivation theory" (2009). Graduate Theses, Dissertations, and Problem Reports. 4534.

https://researchrepository.wvu.edu/etd/4534

This Thesis is protected by copyright and/or related rights. It has been brought to you by the The Research Repository @ WVU with permission from the rights-holder(s). You are free to use this Thesis in any way that is permitted by the copyright and related rights legislation that applies to your use. For other uses you must obtain permission from the rights-holder(s) directly, unless additional rights are indicated by a Creative Commons license in the record and/ or on the work itself. This Thesis has been accepted for inclusion in WVU Graduate Theses, Dissertations, and Problem Reports collection by an authorized administrator of The Research Repository @ WVU. For more information, please contact researchrepository@mail.wvu.edu. 
Encouraging Testicular Self-Examination Behaviors in College Males: Examining the Role of Fear Appeals in Protection Motivation Theory

\author{
Cara L. Slider
}

Thesis submitted to the faculty of the Perley Isaac Reed School of Journalism at West Virginia University

in partial fulfillment of the requirements for the degree of

\author{
Master of Science \\ in \\ Journalism
}

Dr. Diana Martinelli, Chair

Dr. R. Ivan Pinnell

Chuck Harman

Stephen Davis

\title{
Morgantown, West Virginia \\ 2009
}

\author{
Keywords: Testicular Cancer, Testicular Self-Examinations, Protection Motivation \\ Theory, Fear Appeals
}




\title{
Abstract \\ Encouraging Testicular Self-Examination Behaviors in College Males: Examining the Role of Fear Appeals in Protection Motivation Theory
}

\author{
Cara L. Slider
}

Testicular cancer is the most common cancer occurring in males between the ages of 15 $\& 35$. Although testicular cancer holds a survival rate of $99 \%$ when detected and treated early, prior research shows most males do not perform regular testicular selfexaminations. This research examined the role of fear appeals in the revised protection motivation theory (PMT) model to predict the performance of testicular self-examination behaviors in college males. An experiment was conducted among a convenience sample of $156(\mathrm{~N}=156)$ males enrolled in a state university. All males answered a set of questions measuring their threat appraisal concerning testicular cancer- perceived severity, perceived vulnerability- and intentions to perform self-examinations.

Participants were then presented with either a fear appeal or informational message about performing testicular self-examinations and developing testicular cancer. The participants then answered the same set of questions in addition to fear measures. Any differences were noted. Findings, discussion, limitations, and suggestions for future research are included. 


\section{Table of Contents}

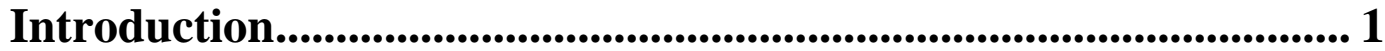

Literature Review ....................................................................................... 3

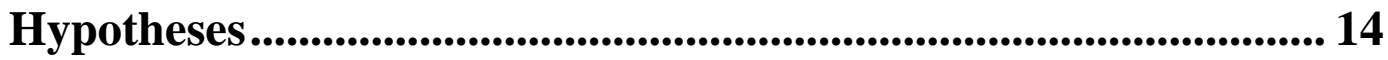

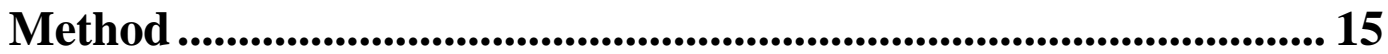

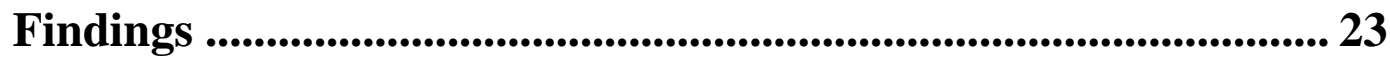

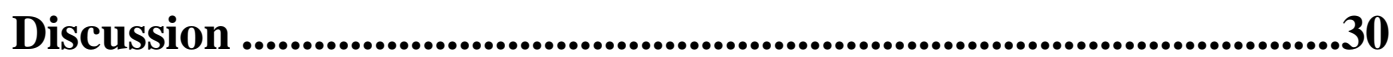

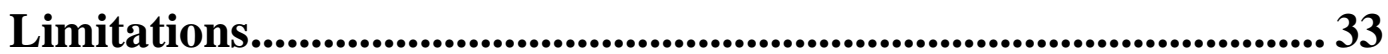

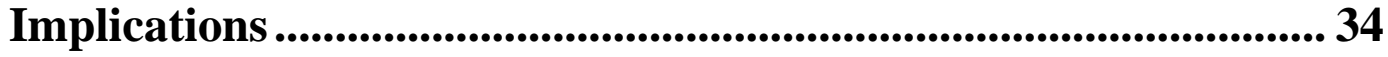

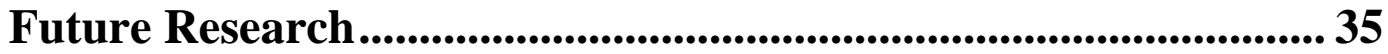

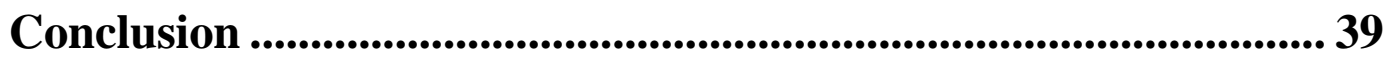

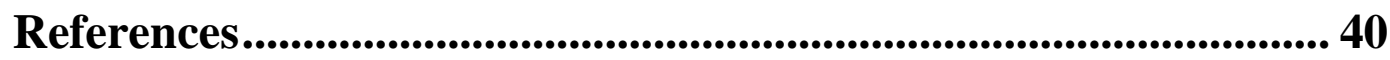

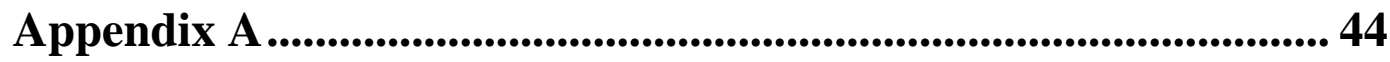

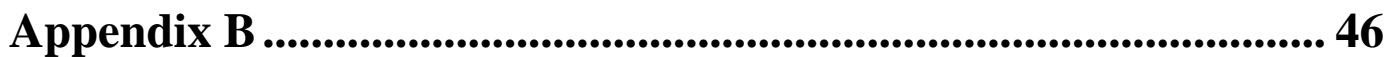

Appendix C ............................................................................................ 48

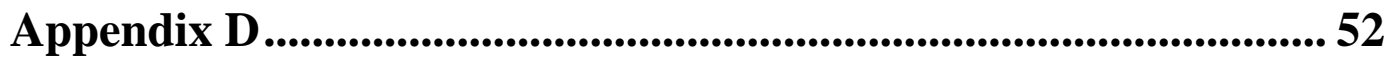

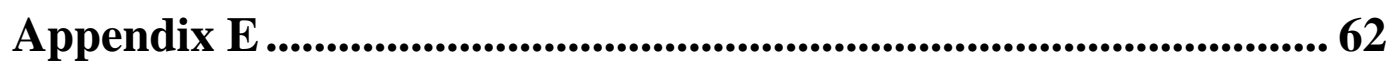

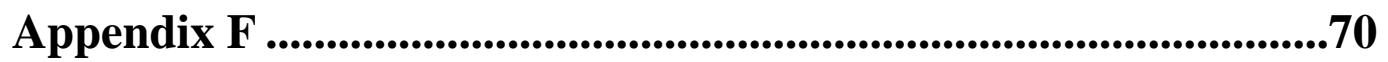




\section{Introduction}

According to the American Cancer Society (2006), testicular cancer is one of the most common cancers in males between the ages of 15 to 35 . Although the explanation is unknown, incidences of testicular cancer continue to rise and the disease remains a leading cause of death in young men (Austoker, 1994; Barling \& Lehmann, 1999). One of the most distinctive features of the condition is its obvious age distribution; it is the most common cancer in young and middle-aged men (Peate, 1999). Another distinctive factor of the disease is the fact that testicular cancer has a remarkably high survival rate when detected early. Unfortunately, more than $50 \%$ of testicular cancer incidences are reported after the disease has spread past its primary site, cutting survival rate by more than half. It has been estimated that more than $90 \%$ of men who finally present a testicular abnormality to a physician put off seeking advice because of "fear or embarrassment .... or a lack of awareness that a potentially serious and progressive illness may arise in the testis" (Austoker, 1994). Based on this information, it is apparent that successful health communication messages need to be created to not only warn men of the risks of waiting to seek medical attention when a lump is found, but to encourage a proactive approach concerning testicular health.

Testicular cancer holds a survival rate of $96 \%$ when it is found early or before the disease spreads to surrounding tissue. Testicular cancer can develop in one or both of a male's testes and usually presents itself as a painless lump, abnormal swelling, or heaviness in the scrotum (American Cancer Society, 2000). A better prognosis is associated with males who find a lump in its early gestation; therefore, early detection of testicular cancer is critical (Umphrey, 2003). The American Cancer Society (2000) 
recommends testicular self-examination as a tool for the early detection of testicular cancer (Umphrey, 2003). Evidence from Katz, Meyers \& Walls (1995) and Moore, Barling \& Hood (1998) suggests that although testicular cancer is primarily found by the individual by accident, males do not regularly perform testicular self-examinations.

During 2008, The American Cancer Society (Cancer.org, 2007) estimates around 8,090 cases of testicular cancer will be diagnosed in the United States. Three hundred and eighty men are estimated to die from the disease in the same year. Although the incidences of the disease have increased in the U.S., testicular cancer is by no means common. The average man has about a one in 300 chance of developing the disease over his lifetime (Cancer.org, 2007). Because the treatment for this disease is largely successful, males have only about a one in 5,000 chance of dying from testicular cancer.

Testicular cancer is one of the most curable forms of cancer; the five-year relative survival rate for all men with this cancer is $96 \%$, according to the National Cancer Institute (2005). The five-year relative survival rate for cancer that has not spread outside of the testicle is $99 \%$; however, for cancer that has spread beyond the surrounding lymph nodes, the survival rate drops to around $70 \%$. According to the American Cancer Society (2007), there are currently around 140,000 men in the U.S. who have survived testicular cancer.

This research will fill a niche in the literature by using the protection motivation theory to gauge males' intentions and attitudes toward testicular self-examination and find whether a high-threat message best motivates this essential behavior. This academic research will aid in health communications and public awareness campaigns. It will benefit many groups, specifically those involved in communication studies and 
preventative health care. This research also has direct implications for all males, especially between the ages of 15 and 35 , and is done with the hopes of encouraging early detection of testicular cancer and the possible saving of lives.

\section{Literature Review}

\section{Testicular Cancer Risk Factors}

The American Cancer Society (2007) defines a risk factor as "anything that changes your chance of getting a disease such as cancer." Over the years, scientists have found risk factors that can contribute to a male's chance of developing testicular cancer; however, it is unknown to what extent each risk factor contributes to the actual development of the disease. It should also be noted that most men who develop testicular cancer do not possess any of the known risk factors (Cancer.org, 2007).

The main risk factor for testicular cancer is cryptorchidism, which is more commonly known as an undescended testicle. According to the American Cancer Society (2007), about $10 \%$ of all testicular cancer cases arise in men with cryptorchidism. In this case, cancer usually forms in the testicle that has not moved down; however, around $25 \%$ of the time cancer forms in the normal testicle which leads many doctors to believe that cryptorchidism is not the cause of testicular cancer. Although it has not been proven, many think that an outside problem causes both the increased cancer risk and the cryptorchidism (Cancer.org, 2007).

Men in the United States and Europe are more likely to develop testicular cancer than men in any other part of the world. Men living in Africa and Asia have the lowest risk for developing the disease. Race can also play a role in the likelihood of testicular cancer development. Caucasian males have five times the chance of developing 
testicular cancer than African American males and three times the chance of Asian males (Cancer.org, 2008). Latino and Hispanic males carry a risk that falls between that of Caucasian and Asian males.

As previously mentioned, age plays a large role in the likelihood that a male will develop testicular cancer. While the cancer can affect men of any age, nine out of 10 times testicular cancer occurs in men between the ages of 20 and 54 (Cancer.org, 2007). Based on the above information, the profile of an average testicular cancer patient is a relatively young, white male that lives in the United States.

\section{Testicular Cancer \& Testicular Self-Examination}

The American Cancer Society (2000) recommends* testicular self-examinations (TSE) as a tool for the early detection of testicular cancer. (*In 2007, due to lack of research correlating reduced death rates and testicular self-exams, the American Cancer Society quit recommending testicular self examinations for all males; only males with specific risk factors for testicular cancer are currently encouraged to perform TSE.) As previously mentioned, although there is evidence that testicular cancer is usually found by oneself by accident, research suggests that most males do not regularly perform testicular self-examinations (Katz et al., 1995; Moore et al., 1998). Studies from Wohl \& Kane (1997) have shown that although female cancer issues are regularly discussed at the secondary school level, male cancer issues seemed to be ignored. The execution of testicular cancer and Testicular Self-Examination education is not only uncommon, but it is virtually non-existent both publicly and in school systems (Steadman \& Quine, 2004). 
Therefore, the development of messages that bring this issue to people's attention and successfully encourage males to perform testicular self-examinations is needed.

Research conducted by Katz et al. (1995) revealed that, compared to women (concerning breast self-examination), men (concerning testicular self-examination) were less likely to know about, see the importance of, and actually perform self-examinations. This study also suggested that the best predictors of cancer awareness and selfexamination behavior were fear of developing cancer and self-rated confidence that selfexamination was being done correctly (Katz et al. 1995). Therefore, this experiment will measure both self-efficacy and amount of fear arousal, among other features associated with protection motivation theory.

\section{Protection Motivation Theory}

Protection motivation theory (PMT) has long been used to study the role of perceived efficacy regarding specific health communication issues (Rogers, 1975, 1983) and the motivations for handling a possible risk. An individual's perceived ability to obtain information needed and communicate is called communication efficacy (Afifi \& Weiner, 2004). PMT contends that individuals will be motivated to protect themselves from a risk if they understand the degree of risk involved (Youn, 2005) and believe they have the means of reducing the risk. With testicular self-examination messages, it therefore becomes important to determine the most effective means of reaching college males to communicate the necessity of performing testicular self-examinations. Studies using the protection motivation theory have been conducted regarding safe sex behavior in college students (Houser, Burns \& Driver, 2007), Internet use behaviors (Larose, Rifon 
\& Wirth, 2007), and in developing anti-smoking campaigns for adolescents (Pechmann, Zhao, Goldberg \& Reibling, 2003) to identify effective message components.

The revised version of protection motivation theory (Rogers, 1983) explains the cognitive mediation process of behavioral change in terms of threat and coping appraisal. Figure 1 illustrates that the model's threat appraisal depends on two factors: 1) perceived severity, or the person's estimate of the severity of the threat, and 2) perceived vulnerability, or the person's estimate of the chance of encountering the threat. The model's coping appraisal consists of: 1) response efficacy, or the individual's expectancy that carrying out recommendations can defeat the threat, and 2) self-efficacy, or belief in one's capability to execute the recommended course of action successfully (Plotnikoff \& Higginbotham, 2002). This revised version of protection motivation theory is an extension of Lazarus' (1968) primary and secondary appraisal process model.

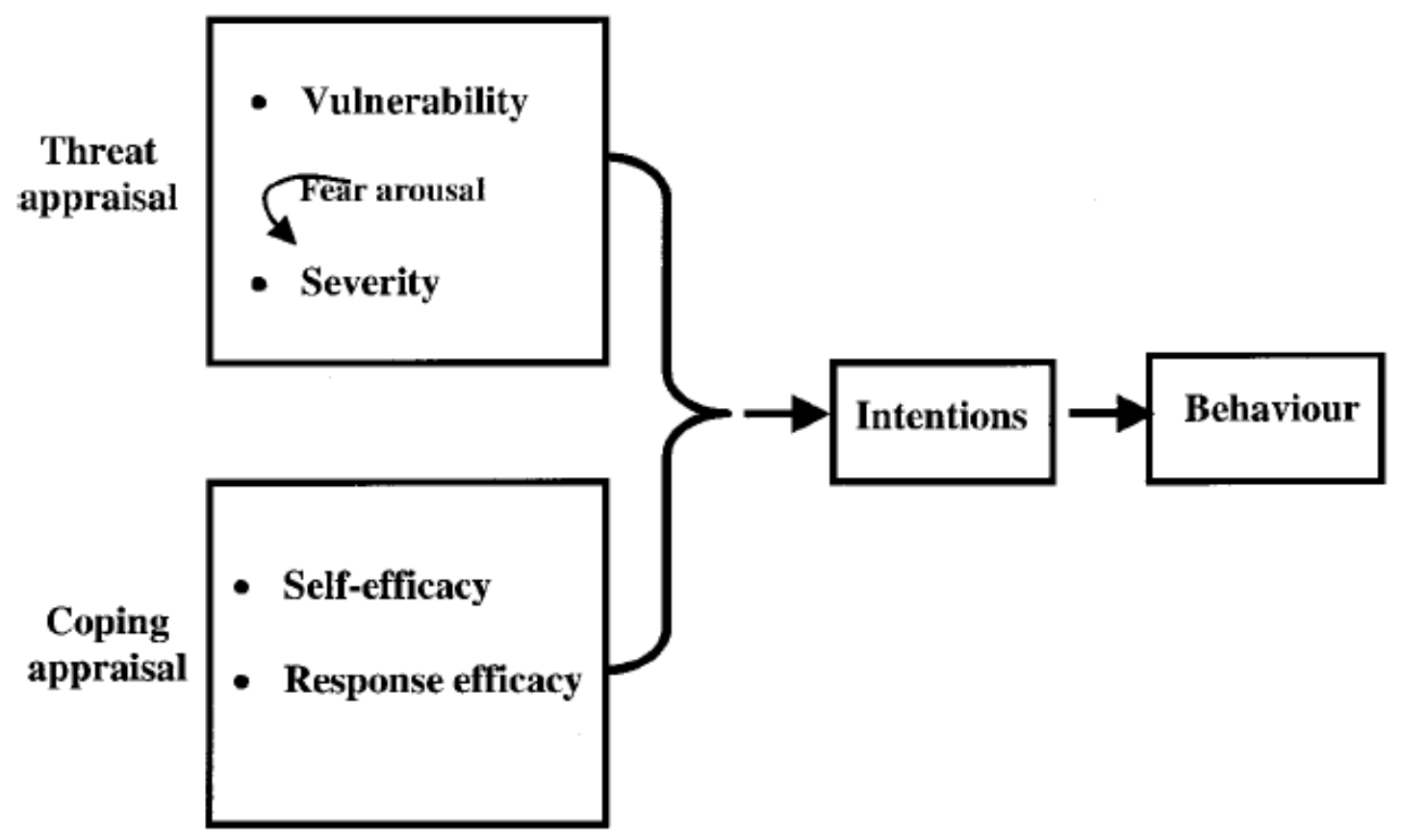

FIG. 1. Basic Protection Motivation Theory Schema. 
In this case, relating to testicular self-examination and testicular cancer, perceived severity relates to a male's feeling that testicular cancer is a brutal disease, and perceived vulnerability relates to the male's feeling of likelihood that he will contract testicular cancer. The response efficacy component of the coping appraisal relates to the male's confidence that performing testicular self-examinations will reduce his risk of death from testicular cancer, and self-efficacy is measured by the male's confidence that he can accurately perform a testicular self-examination.

Research based on protection motivation theory (Maddux \& Rogers, 1983; Rippetoe \& Rogers, 1987; Rogers, 1975, 1983; Tanner, Hunt \& Eppright, 1991; Witte, 1994) suggests four types of messages are especially likely to increase protection motivation, as measured by intentions to engage in the advocated health behavior. Protection motivation theory hypothesizes that the motivation to protect oneself from danger is a positive linear function of the four cognitive beliefs, or mediators, where an individual perceives (as shown above): 1) enhanced perceptions of the severity of the disease consequences, 2) stressed vulnerability to or chances of contracting the disease, 3) the efficacy of the advocated behavior in terms of preventing or curing the disease, and/or 4) their self-efficacy, or confidence, in performing the advocated behavior (Plotnikoff \& Higginbotham, 2002). These four cognitive appraisal processes mediate the choice of a coping behavior. The responses consist of either adapting, whereby the person in question performs the beneficial behavior presented (i.e. performs selfexaminations) or ceases to engage in the dangerous behavior presented (i.e., quits smoking), or maladapting, whereby the person in question avoids the performance of the 
beneficial behavior presented (i.e., does not perform self-examinations) or continues to engage in the dangerous behavior presented (i.e., continues to smoke).

According to the protection motivation model, an emotional state of fear theoretically influences attitudes and behavior change indirectly through the appraisal of the severity of danger (see Figure 1). High threat appraisal results from perceptions of high severity and/or vulnerability and (presumably) inhibits maladaptive behaviors (i.e., not performing testicular self-examination). High coping appraisal stems from confidence in self and/or response efficacy and therefore encourages adaptive behaviors (i.e., performing testicular self-examination behaviors). The outcome of these appraisal processes is an intermediate state called "protection motivation" (Rogers, 1983). A review of health belief studies (Janz \& Becker, 1984) found that each variable included in the protection motivation theory was found to be a predictor of behavior in at least $65 \%$ of pertinent studies reviewed (Pechmann, 2001).

Initially, the strength of protection motivation was assessed through measuring the participants' intentions to adopt the recommended behavior (Plotnikoff \& Higginbotham, 2002). Thus, the cognitive mediators should have significant associations with the intentions to perform the desired behavior. Theory of reasoned action concludes that intention is the major predictor of behavior (Ajzen \& Fishbein, 1989); therefore, a measure of intentions can serve as the indicator to whether or not protection motivation has occurred.

Testicular cancer knowledge and testicular self-examination intentions have previously been studied using prospect theory (Umphrey, 2003), the extended parallel process model (Morman, 2000), and the health action process approach (Barling \& 
Lehmann, 1999). Umphrey’s (2003) research tested message framing (gain vs. loss) against message processing (high vs. low) with the theoretical frame of prospect theory. She found that males exposed to a loss frame message felt a greater perceived susceptibility to testicular cancer than males exposed to a gain frame message. Umphrey's (2003) research also concluded that males who were exposed to a loss frame message and engaged in greater message processing harbored more positive attitudes toward testicular self-examinations than males who received a gain frame message and engaged in low depth of message processing (Umphrey, 2003).

Using the extended parallel process model, Morman (2000) tested message type (fact vs. narrative) against level of efficacy (high vs. low) concerning testicular selfexamination intentions. In line with previous findings, Morman (2000) found that men exposed to high threat/high efficacy messages were reportedly more motivated to perform TSE than men exposed to high threat/low efficacy models. Morman's (2000) research also supported the proposed hypothesis that knowledge about how to perform a testicular self-examination is positively correlated with men's positive attitudes about testicular self-examination and intentions to perform testicular self-examination.

Barling and Lehmann (1999) used the health action process approach to find the best predictors of males' testicular self-examination performance. In line with previous research using both the health action process approach and the theory of reasoned action, they found that intention was indeed the best predictor of performance, with self-efficacy identified as the second best predictor of performance (Barling \& Lehmann, 1999). 


\section{Role of Emotion / Fear Appeal}

Research conducted by Tanner et al. (1991) cited a weakness in the protection motivation theory; they point out a failure in the original PM model to "recognize the importance of emotional response to fear appeals.” Folkman, Schafer \& Lazarus (1979), Friestad \& Thorson (1985), and Ray \& Batra (1983) contend that emotion may increase both belief in and attention to a persuasive message (Tanner et al., 1991). This increases the audiences' likelihood to continue processing threat-related information, which ultimately leads to an increase in the probability of adaptive behavior. In other words, fear is not necessary, but the presence of fear arousal will theoretically heighten cognitive threat appraisals and subsequently heighten drive.

According to Tanner et al. (1991), the most important aspects to consider when crafting a fear appeal, or high-threat message, are the cognitive processes concerned with responding to threats, as well as arousing an emotional state of fear. In order to make the appeal effective, the audience should be presented with information that emphasizes the following:

- the severity of the threat being presented;

- the probability of the threat's occurrence;

- the effectiveness of a particular coping response; and

- the ease with which that coping response can be implemented (Tanner et al., 1991).

Coinciding with the revised protection motivation theory, the information in the message should be ordered in line with cognitive responses; in other words, the threat information should precede the coping information. 
The revised protection motivation theory cites fear arousal as a foremost cause of perceived severity. As protection motivation theory states, the deeper the level of perceived severity and/or vulnerability involved in the threat appraisal, the greater effect this will have on a person's intentions. Therefore, the greater the fear communicated in a message, the greater effect this will have on intentions.

Janis's (1967) curvilinear theory supports the widely-accepted belief that a moderate fear appeal is a more effective persuasive tool than a weak or strong fear appeal. Janis (1967) contended that a "too strong" fear appeal can create too much tension and drive, while weak appeals create too little tension and drive. Therefore, Janis (1967) proposed that the fear/persuasion relationship could be best represented by an inverted U-shaped curve indicating moderate fear levels to be optimal. Inconsistencies have been found regarding the effect of fear appeals since Janis (1967); however, more recent studies have found that fear is positively related to persuasion (Laroche, Toffoli, Zhang \& Pons, 2001), rejecting Janis's (1967) earlier contention that the most effective fear appeal is a moderate fear appeal. Since results are mixed concerning the optimal level of fear arousal for behavior change, this research will test only two messages: one that arouses fear, or a high-threat message (crafted according to the elements cited by Tanner et al.), and one that does not, or a low-threat message.

According to Rogers (1983), fear may occur but is not considered necessary to influence behavior. Research by Ray and Wilkie (1970) concluded that in many cases fear heightens drive. This drive would subsequently lead to greater interest in the presented message and theoretically increase intentions to adopt the presented beneficial behavior/cease in engaging in negative behavior presented, but is not so in all cases. In 
the best case scenario, researchers can conclude that fear appeals occasionally affect persuasion and behavior (Tanner et al., 1991). Although fear arousal is not necessary to facilitate behavior and intention change, Tanner et al. acknowledged that evoking fear arousal hypothetically heightens cognitive threat appraisal. Noting the limitations of the protection motivation theory's failure to include fear directly, Tanner et al. (1991) authored a revised protection motivation theory suggesting that fear appeals be included to heighten drive.

Research based on revised protection motivation theory has also yielded mixed results. Dillard and Anderson (2004) conducted research concerning fear appeals on intentions to obtain an influenza vaccination after presenting messages about the dangers of influenza. This experiment used revised protection motivation theory to test fear appeals; the success of the fear appeal was measured by intentions to obtain a flu vaccination. Dillard and Anderson (2004) found that the amount of fear produced by the message was a considerable predictor of persuasion.

Research conducted by Dukeshire (1996) examined how fear appeals influence behavior regarding sun exposure, the primary cause of skin cancer, using revised protection motivation theory. Dukeshire (1996) found that the fear appeals were significantly more effective on changing sun protection attitudes, beliefs and intentions than thinking and writing about the effects of sun exposure and receiving no intervention. Dukeshire (1996) also found that a high fear appeal was more effective in changing the attitudes, intentions and beliefs in a high risk population of regular sunbathers than a low fear appeal. The results revealed that participants that cited the greatest level of fear 
arousal demonstrated the greatest changes in sun protection attitudes, beliefs and intentions.

In 2001, Laroche et al. examined the use of fear appeals in protection motivation theory regarding cigarette advertising across cultures in Chinese and Anglos. This study attempted to examine the difference in effectiveness of fear appeals across cultures. The researchers tested both physical threat appeals and social threat appeals on participants. The results showed that the physical threat appeal had a much greater affect on the Anglos examined than on the Chinese (Laroche et al., 2001). For the Chinese participants, fear arousal positively affected behavior intentions for the future; however, this future intention was not show in the Anglo participants, whose more immediate intentions were affected.

The results of studies examining the role of the fear appeal in revised protection motivation model have yielded mixed results; in most cases, increase in fear arousal is positively correlated to an increase in intentions to perform the risk-evading behavior. According to the previous research examined, the revised protection motivation theory has been used to measure attitudes and intentions regarding many health issues, including exercise, sun protection, condom use, and smoking; however, the revised protection motivation theory has not examined testicular self-examination behaviors in college-aged males. Therefore, this research will use the revised protection motivation theoretical lens to examine testicular self-examination intentions in a convenience sample of males on a college campus. The success of fear appeals will be tested to theoretically increase cognitive threat appraisal. In turn, the increase in cognitive threat appraisal will lead to greater intentions to perform testicular self-examination. This study will test the 
assumption that an increased cognitive threat appraisal (by means of a fear appeal, or high-threat message) accompanied by an increased cognitive coping appraisal (by means of a diagram) will increase participants' intentions to perform testicular selfexaminations.

\section{Hypotheses}

Based on the reviewed literature concerning protection motivation theory and TSE, the following hypotheses will be tested:

H1: Participants exposed to a fear appeal, or high-threat message, will experience a greater increase in perceived severity of testicular cancer than males exposed to an informative message with a diagram. This is predicted because, according the revised protection motivation theory, fear arousal will increase a person's feelings of severity regarding the subject presented (in this case, testicular cancer).

H2: Participants exposed to a fear appeal, or high-threat message, will experience a greater increase in perceived vulnerability than males exposed to the informative message with a diagram. This is predicted because, according to the revised protection motivation theory, fear arousal will increase a person's feelings of vulnerability regarding the subject presented (in this case, testicular cancer).

H3: Participants exposed to a fear appeal, or high-threat message, will experience a greater change in intentions to perform testicular self-examinations than males exposed to an informative message with diagram. This is predicted in accordance with the revised protection motivation theory, which states that fear heightens drive. In this case, I will 
examine whether or not fear (as measured by high perceived vulnerability and perceived severity) is positively correlated with participants' intentions to perform testicular selfexaminations.

\section{Method}

\section{Participants}

For the purpose of this research, IRB approval (see Appendix A) was gained for an experiment that involved the implementation of two surveys to a convenience sample of at least 130 male students $(\mathrm{N}=130)$ enrolled in Journalism courses at West Virginia University's P. I. Reed School of Journalism to determine their intentions concerning testicular self-examinations before and after exposure to a fear-based or informational message. A sample size of 130 students was chosen based on the sample size calculator piface with a two-tailed alpha of .05 at a power level of .80 (to capture a "medium" effect) (Lenth, 2006). A sample of this size is large enough to support causation (Lenth, 2006). The experiment took the participants fewer than ten minutes to complete. In return for completing the experiment, students earned extra credit in their respective classes. The School of Journalism has an IRB-approved extra credit policy in place (see Appendix B). The female students, as well as males who declined to participate, were offered another extra credit assignment at the time of the study.

\section{Experimental Design}

For the purpose of this study, a basic pre-test/posttest experimental design was utilized.

$$
\text { Pretest } \rightarrow \text { Experimental Treatment } \rightarrow \text { Posttest }
$$


The basic experimental design was chosen for several reasons. First, this is the only design that boasts evidence of causality (Wimmer \& Dominick, 2006). Also, this design ensures that any cause noted precedes the effect. By measuring attitudes and intentions before and after the participant in a controlled environment is exposed to the experimental messages, any effects can be attributed to the message in question. This is a $2 \mathrm{X} 1$ design, testing the effects of fear appeals (neutral vs. fear message) on intentions to adopt testicular self-examination behavior. While the independent variable (message exposure) consisted of either a neutral or fear-based message, the dependent variable consisted of intentions to perform testicular self-examinations (initially measured with an index of three questions that statistically held together, $\alpha=.93$ ). Any index measures that did not statistically hold together (i.e. alpha of at least .70) were dropped (Dominick \& Wimmer, 2006). Because the manipulation check sample size was so small, one measure which approached the $\alpha=.70$ level at .69 , was retained.

This experiment measured perceived vulnerability to the disease, perceived severity of it, and intentions by means of participants' answers to questions concerning testicular selfexaminations before and after being exposed to the experimental message. The messages were developed in line with recommendations from Tanner et al, 1991, with the threat information preceding the coping information. Recommendations were followed from Morman (2000), and the fear appeal included personalistic and vivid language. Specific information was included in both messages to enhance the readers' perceptions of vulnerability and severity of testicular cancer and self-efficacy and response efficacy concerning testicular self-examinations. The fear message, however, emphasized the 
personal effects of the disease. The results reflected whether or not the message with a fear appeal elicited a greater change in intentions and attitudes.

According to the revised protection motivation theory, those participants exposed to a fear-based message should experience a higher level of severity, vulnerability, and, therefore, stronger intentions in the post-test. A diagram on how to successfully perform a testicular self-examination and reasons to perform testicular self-examination was included in all the messages to increase participants' self-efficacy, or the confidence one has in adopting the course of action successfully, and response-efficacy, or the confidence one has in the action defeating the presented threat. (The effectiveness of the diagram was measured in the manipulation check, discussed below.)

Fig. 1. Experimental Conditions

\begin{tabular}{|l|l|}
\hline Neutral Message with Diagram & Fear-based Message with Diagram \\
\hline
\end{tabular}

\section{Manipulation Checks}

To ensure the internal validity of the survey questions to elicit consistent perceptions of self-efficacy and response efficacy in the final experiment, and to ensure a legitimate fear appeal is being used, a manipulation check (Appendix D) was conducted among $11.5 \%$ of the recommended sample size (or 15 males). A small sample size for the manipulation checks was chosen in accordance with research conducted by Gore \& Bracken (2005), who used a manipulation check sample size of 12 ( $N=12)$ for a study with a total sample size of $145(\mathrm{~N}=145)$. The pretest presented either a fear message or informative message, and participants were asked a set of questions before and after 
message exposure that measured all components of the protection motivation theory fear, perceived vulnerability, perceived severity, self-efficacy, response efficacy and intentions - to ensure that all measures were accurately accounted for. Males who completed the pretest survey were asked for feedback regarding the clarity and meaning of the questions, and a "confusing" vulnerability measure was dropped as a result.

The results were analyzed with paired sample t-tests (to test pre- and post-test means within groups) and independent sample post-test t-tests (to measure mean differences between the two groups.) After the initial manipulation check, one of the measures for severity ("The impact of testicular cancer be severe on someone my age") was dropped because of a weak correlation with the other two severity measures, leaving two measures for severity $(\alpha=.69)$. Also, a measure for vulnerability ("I feel vulnerable to the possibility of testicular cancer affecting me personally") was dropped due to a weak reliability with the other vulnerability measure, leaving one measure for vulnerability. Questions for self-efficacy and response efficacy were modeled after previous research that measured these concepts and demonstrated an acceptable alpha of reliability. High measures of self-efficacy and response efficacy were recorded by both groups with no statistically significant t-test differences, so no change was made to the questions or to the diagram or instructions on how to perform a testicular selfexamination (response efficacy question $1=t(13)=.398, p=.69, d=.33$; response efficacy question $2=t(13)=1.18, p=.25, d=1.01$; self-efficacy questions $1=t(14)=$ $1.36, p=.19, d=1.5$; and self-efficacy question $2=t(14)=.79, p=.44, d=1.0$.

Next, a second manipulation check was conducted, after changes as a result of the first manipulation check findings were incorporated to elicit different fear levels between 
the two groups. (To elicit a higher arousal of fear arousal from the fear appeal message, it was enhanced using more personal language like "you" and bold typeface.) This manipulation check consisted of $17 \%$ of the recommended sample size (or 22 males). The results of the second manipulation check approached a statistically significant difference between the fear arousal measures in the fear and no fear groups in one measure $(t(20)=$ $1.80, p=.087, d=1.36)$

Table 1. Manipulation Check 2 Statistics for Fear Arousal

\begin{tabular}{|cc|c|c|c|c|}
\hline & Version & $\mathrm{N}$ & Mean & Std. Deviation & $\begin{array}{c}\text { Std. Error } \\
\text { Mean }\end{array}$ \\
\hline fear1 & fear & 11 & 5.0909 & 1.51357 & .45636 \\
& nofear & 11 & 4.0000 & 1.78885 & .53936 \\
fear2 & fear & 11 & 5.2727 & 1.42063 & .42834 \\
& nofear & 11 & 3.9091 & 2.07145 & .62457 \\
fear3 & fear & 11 & 4.9091 & 1.57826 & .47586 \\
& nofear & 11 & 4.0909 & 1.37510 & .41461 \\
\hline
\end{tabular}

One of the measures for fear ('I feel frightened about the subject of testicular cancer') was dropped from the questionnaire due to low reliability with the other two fear measures $(\alpha<.70)$. Statistically speaking, all other index measures held together. Also, it was clear that the message again elicited high self-efficacy and response efficacy from all participants with no statistically significant differences found using independent sample ttests on these dimension responses (see tables 2-8); therefore, the messages remained constant but the questions measuring coping appraisal were dropped from the questionnaire, as they were not included as a measure in the hypotheses.

Table 2. Manipulation Check 1, Response Efficacy 1

\begin{tabular}{|c|c|c|c|c|c|}
\hline & Version & $\mathrm{N}$ & Mean & Std. Deviation & $\begin{array}{l}\text { Std. Error } \\
\text { Mean }\end{array}$ \\
\hline \multirow[t]{2}{*}{ responseefficacy } & fear & 8 & 5.3750 & 1.99553 & .70553 \\
\hline & nofear & 8 & 5.0000 & 1.06904 & .37796 \\
\hline
\end{tabular}


Table 3. Manipulation Check 1, Response Efficacy 2

\begin{tabular}{|c|c|c|c|c|c|}
\hline & Version & $\mathrm{N}$ & Mean & Std. Deviation & $\begin{array}{l}\text { Std. Error } \\
\text { Mean }\end{array}$ \\
\hline \multirow[t]{2}{*}{ responseefficacy } & fear & 8 & 5.8750 & 1.12599 & .39810 \\
\hline & nofear & 8 & 4.5000 & 1.92725 & .68139 \\
\hline
\end{tabular}

Table 4. Manipulation Check 1, Self-Efficacy 1

\begin{tabular}{|c|c|c|c|c|c|}
\hline & Version & $\mathrm{N}$ & Mean & Std. Deviation & $\begin{array}{l}\text { Std. Error } \\
\text { Mean }\end{array}$ \\
\hline \multirow[t]{2}{*}{ selfefficacy } & fear & 8 & 5.3750 & 2.19984 & .77776 \\
\hline & nofear & 8 & 4.8750 & 1.95941 & .69276 \\
\hline
\end{tabular}

Table 5. Manipulation Check 1, Self-Efficacy 2

\begin{tabular}{|c|c|c|c|c|c|}
\hline & Version & $\mathrm{N}$ & Mean & Std. Deviation & $\begin{array}{l}\text { Std. Error } \\
\text { Mean }\end{array}$ \\
\hline \multirow[t]{2}{*}{ selfefficacy } & fear & 8 & 5.3750 & 2.19984 & .77776 \\
\hline & nofear & 8 & 5.2500 & 1.90863 & .67480 \\
\hline
\end{tabular}

Table 6. Manipulation Check 2, Response Efficacy 2

\begin{tabular}{|ll|r|r|r|r|}
\hline & Version & $\mathrm{N}$ & Mean & Std. Deviation & $\begin{array}{c}\text { Std. Error } \\
\text { Mean }\end{array}$ \\
\hline responseefficacy2 & fear & 11 & 5.7273 & 1.00905 & .30424 \\
& nofear & 11 & 5.8182 & 1.25045 & .37703 \\
\hline
\end{tabular}

Table 7. Manipulation Check 2, Self-Efficacy 1

\begin{tabular}{|ll|r|r|r|r|}
\hline & Version & $\mathrm{N}$ & Mean & Std. Deviation & $\begin{array}{c}\text { Std. Error } \\
\text { Mean }\end{array}$ \\
\hline selfefficacy1 & fear & 11 & 4.7273 & 2.00454 & .60439 \\
& nofear & 11 & 5.2727 & .90453 & .27273 \\
\hline
\end{tabular}

Table 8. Manipulation Check 2, Self-Efficacy 2

\begin{tabular}{|ll|r|r|r|r|}
\hline & Version & $\mathrm{N}$ & Mean & Std. Deviation & $\begin{array}{c}\text { Std. Error } \\
\text { Mean }\end{array}$ \\
\hline selfefficacy2 & fear & 11 & 4.9091 & 1.86840 & .56334 \\
& nofear & 11 & 5.1818 & .87386 & .26348 \\
\hline
\end{tabular}


The final experiment was designed to measure the participants' post-test threat appraisals (perceived vulnerability and perceived severity), intentions and fear. Questions about demographics, prior knowledge and class rank were also included for discussion.

\section{Self-Efficacy \& Response Efficacy}

As previously mentioned, self-efficacy and response efficacy were measured in both manipulation checks; from the results, it was clear that the instructions on how to accurately perform a testicular self-exam and diagram, which remained constant, elicited high levels of self-efficacy and response efficacy.

It was clear that the instructions and diagram elicited similarly high measures of selfefficacy and response efficacy based on a lack of differences in the post-test means. Selfefficacy and response efficacy are necessary in order for protection motivation to take place. Because of the consistent findings between both groups in both manipulation tests, these measures were dropped from the questionnaire for the actual experiment so the threat appraisal alone, consisting of severity and vulnerability, was measured. The hypotheses contended that males who received the fear appeal (or high-threat message) would experience greater perceived severity of testicular cancer, greater perceived vulnerability to testicular cancer and greater intentions to perform testicular selfexaminations. As long as self-efficacy and response efficacy were constants, the threat appraisals could be manipulated and analyzed.

\section{Experiment Implementation}

One hundred and sixty participants $(\mathrm{N}=160)$ from two journalism courses (Journalism 101 and Advertising 201) completed the experiment on March 2 and March 5, 2009. Four surveys were thrown out due to incomplete answers, leaving a total sample 
of 156 participants $(\mathrm{N}=156)$. The students signed IRB consent forms before participating in the experiment (see Appendix C). To eliminate the influence of extraneous variables, the experimenter utilized randomization, or randomly assigned participants, to different treatment groups (Wimmer \& Dominick, 2006). To ensure randomization, the surveys were collated and then distributed to the sample. Each participant had an equal chance of being assigned to a fear or neutral message. The experiment presented an artificial environment and measured factors based on participants' self-reporting, and the results will therefore be scrutinized according to limitations associated with this method. However, experiments by their nature can be regarded as taking place in "artificial environments." This is so the behavior under investigation can be placed under proper control and measured (Wimmer \& Dominick, 2006).

First, participants completed the pretest survey to measure their attitudes, intentions, and prior knowledge concerning testicular cancer and testicular selfexaminations. Participants were then exposed to (and instructed to read thoroughly) a message about testicular self-examinations. After participants read the experimental messages, they were asked to again complete a survey that measured their attitudes and intentions concerning testicular cancer and testicular self-examinations, as well as demographics. At the conclusion of the study, all participants were debriefed on the nature of the study by the experimenter. Participants received a pamphlet about men's health, a testicular cancer fact sheet and a shower hanger depicting how to perform a testicular self-examination from the Urologic Research Institute in Wheeling, West Virginia, and a thank you note from the experimenter with contact information. The note 
encouraged the participants to contact the experimenter with any questions, concerns or to obtain a copy of the research results.

To analyze the survey results, data were entered into a computer-based statistics program, SPSS. The results were tested for statistical differences using paired sample pre- versus post-test and independent post-test t-tests, as well as analysis of variance (ANOVA) using F statistics, when applicable. The research committee chair oversaw and assisted in the statistical analysis for reliability.

Appendix D represents a copy of the survey questions and messages used in the first manipulation check. Appendix E represents a copy of the adjusted survey questions and messages that were tested with the second manipulation check. Appendix F represents a copy of the survey questions and messages that were used in the actual experiment.

\section{Findings}

Hypothesis one contended that participants exposed to a fear appeal, or highthreat message, will experience a greater increase in perceived severity of testicular cancer than males exposed to a neutral, or low-threat, message. This hypothesis was not supported. Analysis of variance for the severity dimension showed no statistical significance between groups. Severity was assessed using two measures; the first measure of severity was "Testicular cancer would be one of the worst things that could happen to me," which yielded an F-statistic of $F(1,154)=.038, p=.84$. The second measure of severity was "The negative aspects of testicular cancer feel serious to me," which yielded an F-statistic of $F(1,154)=.305, p=.58$. 
Hypothesis two contended that participants exposed to a fear appeal, or highthreat message, will experience a greater increase in perceived vulnerability than males exposed to a neutral, or low-threat, message. This hypothesis was not supported. A t-test for vulnerability showed no statistically significant difference between group means for this dimension which was assessed using one measure: "It is likely that testicular cancer will affect me, $" t(154)=-.43, p=.66, d=-.10$.

Finally, hypothesis three contended that participants exposed to a fear appeal, or high-threat message, will experience a greater change in intentions to perform testicular self-examinations than males exposed to a neutral, or low-threat, message. This hypothesis was not supported. Analysis of variance for the intentions dimension showed no statistically significant difference between groups. Intentions were assessed using three measures; the first measure of intentions, "I plan to perform testicular selfexaminations regularly in the next six months," yielded an F-statistic of $F(1,154)=1.60$, $p=.20$. The second measure of intentions, "It is likely I will perform testicular selfexaminations regularly in the next six months," $F(1,154)=.63, p=.42$. The final measure for intentions, "I intend to perform testicular self-examinations regularly in the next six months," yielded an F-test of $F(1,154)=.62, p=.43$.

\section{Prior Knowledge}

The sample for this experiment was primarily made up of Caucasians (83\%), followed by some African Americans (6\%), a few Asians (3\%), followed by 2\% "other" and $1 \%$ Latino. Most participants (97\%) were between the ages of eighteen and twentythree; only $2 \%$ were between the ages of twenty-four and twenty-six and $1 \%$ were between the ages of twenty-seven and twenty-nine. 
Questions to measure participants' prior knowledge of testicular cancer and their performance of testicular self-examination (i.e., "Does testicular cancer affect males your age?" and "Have you ever performed a testicular self-examination?") were asked with response choices of "yes," "no," and "don’t know." Sixty percent of respondents knew that testicular cancer affects males their age; surprisingly, $28 \%$ of the respondents didn't know whether or not testicular cancer affects their age group. Eleven percent of the respondents wrongly responded that testicular cancer does not affect males their age (see Table 9). These particular responses are evidence that testicular cancer education is not currently provided but needed.

Table 9. Prior Knowledge

\begin{tabular}{|c|c|c|c|c|}
\hline Affect your age & Frequency & Percent & Valid Percent & $\begin{array}{c}\text { Cumulative } \\
\text { Percent }\end{array}$ \\
\hline Valid & 1 & .6 & .6 & .6 \\
\hline Yes & 95 & 60.9 & 60.9 & 61.5 \\
\hline No & 17 & 10.9 & 10.9 & 72.4 \\
\hline Don't Know & 43 & 27.6 & 27.6 & 100.0 \\
\hline Total & 156 & 100.0 & 100.0 & \\
\hline
\end{tabular}

In response to whether or not they had ever performed a testicular self-examinations, $64 \%$ responded that they had examined their testicles for lumps and abnormalities, while $35 \%$ had not (see Table 10).

Table 10. Prior TSE Performance

\begin{tabular}{|c|c|c|c|c|}
\hline Performed an exam & Frequency & Percent & Valid Percent & $\begin{array}{c}\text { Cumulative } \\
\text { Percent }\end{array}$ \\
\hline $\begin{array}{ll}\text { Valid } & \text { Yes }\end{array}$ & 99 & 63.5 & 63.5 & 63.5 \\
\hline No & 55 & 35.3 & 35.3 & 98.7 \\
\hline Don't Know & 2 & 1.3 & 1.3 & 100.0 \\
\hline Total & 156 & 100.0 & 100.0 & \\
\hline
\end{tabular}




\section{Vulnerability}

I will now look more closely at the findings for each experiment dimension. As stated previously, vulnerability was assessed using one measure, "It is likely that testicular cancer will affect me." While it was hypothesized that participants in the fear condition would report greater feelings of perceived vulnerability, this was not the case. Similar measures of perceived vulnerability were recorded by both the fear and neutral conditions (see Table 11).

Table 11. Vulnerability Measure

\begin{tabular}{|cc|c|c|c|c|}
\hline & Version & $\mathrm{N}$ & Mean & Std. Deviation & $\begin{array}{c}\text { Std. Error } \\
\text { Mean }\end{array}$ \\
\hline LikelyAffect & Fear & 77 & 3.4675 & 1.54396 & .17595 \\
& No Fear & 79 & 3.5696 & 1.36517 & .15359 \\
\hline
\end{tabular}

It should be noted that a statistically significant difference was found in the paired samples T-test $(t(76)=-2.05, p=.04)$ in the fear condition regarding vulnerability (see Table 12 and Table 13).

Table 12. Fear Group Vulnerability Measure (Paired Sample)

\begin{tabular}{|c|c|c|c|c|c|}
\hline \multicolumn{2}{|c|}{ Fear Condition } & Mean & $\mathrm{N}$ & Std. Deviation & $\begin{array}{l}\text { Std. Error } \\
\text { Mean }\end{array}$ \\
\hline \multirow[t]{2}{*}{ Pair 1} & LikelyAffect & 3.1948 & 77 & 1.35762 & .15472 \\
\hline & LikelyAffect & 3.4675 & 77 & 1.54396 & .17595 \\
\hline
\end{tabular}

Table 13. No Fear Group Vulnerability Measure

(Paired Sample)

\begin{tabular}{|c|c|c|c|c|}
\hline No Fear Condition & Mean & $\mathrm{N}$ & Std. Deviation & $\begin{array}{c}\text { Std. Error } \\
\text { Mean }\end{array}$ \\
\hline Pair 1 LikelyAffect & 3.4177 & 79 & 1.19408 & .13434 \\
\hline LikelyAffect & 3.5696 & 79 & 1.36517 & .15359 \\
\hline
\end{tabular}




\section{Severity}

As stated previously, severity was assessed using two measures with independent samples post-test $\mathrm{T}$-test. Although hypotheses contended that a statistically significant higher measure of perceived severity would be reported by the fear condition, this was not the case (see Table 14). The first measure of severity was "Testicular cancer would be one of the worst things that could happen to me," and the means were almost equal in both conditions. The second measure for severity, "The negative aspects of testicular cancer feel serious to me," yielded nearly equal means in both conditions as well (see Table 15).

Table 14. Severity Measure 1

\begin{tabular}{|ll|r|r|r|r|}
\hline & Version & $\mathrm{N}$ & Mean & Std. Deviation & $\begin{array}{c}\text { Std. Error } \\
\text { Mean }\end{array}$ \\
\hline WorstThings & Fear & 77 & 5.9870 & 1.36202 & .15522 \\
& No Fear & 79 & 5.9494 & 1.03650 & .11662 \\
\hline
\end{tabular}

Table 15. Severity Measure 2

\begin{tabular}{|ll|r|r|r|r|}
\hline & Version & $\mathrm{N}$ & Mean & Std. Deviation & $\begin{array}{c}\text { Std. Error } \\
\text { Mean }\end{array}$ \\
\hline FeelSerious & Fear & 77 & 6.0390 & 1.31231 & .14955 \\
& No Fear & 79 & 5.9367 & .97851 & .11009 \\
\hline
\end{tabular}

Fear

As previously stated, the second manipulation check approached statistical significance difference between the fear appeal and informative messages in an independent post-test T-test. The actual difference in fear captured in the experiment was not significantly different (see Table 16). Although the means for intentions did 
increased with the participants in the fear condition in accordance with the hypotheses, fear cannot be cited as the specific cause of increased intentions, as the differences were small.

Table 16. Fear Measure

\begin{tabular}{|ll|r|r|r|r|}
\hline & Version & $\mathrm{N}$ & Mean & Std. Deviation & $\begin{array}{c}\text { Std. Error } \\
\text { Mean }\end{array}$ \\
\hline FearAffectingMe & Fear & 77 & 4.5325 & 1.72126 & .19616 \\
& No Fear & 78 & 4.4615 & 1.37409 & .15558 \\
\hline
\end{tabular}

\section{Intentions}

The dependent variable in this experiment was intentions. It was hypothesized that intentions to perform testicular self-examinations would increase as each of the following measures increased: perceived vulnerability, perceived severity and fear arousal. In the second manipulation check, vulnerability, severity and fear remained constant. Nearly equal means for intentions resulted as well.

The first measure for intentions ("I plan to perform testicular self-examinations regularly in the next six months") yielded a mean of 4.3 in the fear condition and a mean of 3.9 in the neutral condition (see Table 17). The second measure for intentions ("It is likely I will perform testicular self-examinations regularly in the next six month") yielded a mean of 4.7 in the fear condition and a mean of 4.4 in the neutral condition (see Table 18). The third measure for intentions ("I intend to perform testicular selfexaminations regularly in the next six months") yielded a mean of 4.3 in the fear condition and a mean of 4.1 in the neutral condition (see Table 19). Although the fear group means are consistently higher, none of the intentions differences were statistically significant. A slight increase in intentions was also found post-test among the fear 
condition respondents; however, it was not statistically significant. Also, none of these increases can be attributed to fear (as the hypotheses contended) as the fear measures were almost equal in both fear and neutral conditions.

Table 17. Intentions Measure 1

\begin{tabular}{|c|c|c|c|c|c|}
\hline & Version & $\mathrm{N}$ & Mean & Std. Deviation & $\begin{array}{l}\text { Std. Error } \\
\text { Mean }\end{array}$ \\
\hline \multirow[t]{2}{*}{ PlanToPerform } & Fear & 77 & 4.2987 & 1.89920 & .21643 \\
\hline & No Fear & 79 & 3.9241 & 1.79581 & .20204 \\
\hline
\end{tabular}

Table 18. Intentions Measure 2

\begin{tabular}{|c|c|c|c|c|c|}
\hline & Version & $\mathrm{N}$ & Mean & Std. Deviation & $\begin{array}{l}\text { Std. Error } \\
\text { Mean }\end{array}$ \\
\hline \multirow[t]{2}{*}{ LikelyToPerform } & Fear & 77 & 4.6883 & 1.98852 & .22661 \\
\hline & No Fear & 79 & 4.4430 & 1.85187 & .20835 \\
\hline
\end{tabular}

Table 19. Intentions Measure 3

\begin{tabular}{|c|c|c|c|c|c|}
\hline & Version & $\mathrm{N}$ & Mean & Std. Deviation & $\begin{array}{l}\text { Std. Error } \\
\text { Mean }\end{array}$ \\
\hline \multirow[t]{2}{*}{ IntendToPerform } & Fear & 77 & 4.3247 & 2.00290 & .22825 \\
\hline & No Fear & 79 & 4.0886 & 1.71860 & .19336 \\
\hline
\end{tabular}




\section{Discussion}

The primary objective of this experiment was to assess the utility of fear appeals in the revised protection motivation theory (Tanner et al, 1991) concerning testicular selfexamination behaviors of college males. The results did not support the first hypothesis that males exposed to a fear message would report higher measures of severity than those exposed to an informative message. Males in both groups reported high feelings of perceived severity regarding testicular cancer both before and after exposure to the experimental messages.

Hypothesis two contended that males exposed to a fear message would have greater feelings of perceived vulnerability toward testicular cancer than males exposed to an informative message. Hypothesis two was not supported. Males in both groups reported similarly neutral feelings toward their vulnerability to testicular cancer both before and after message exposure. Hypothesis three, which stated that participants exposed to a fear appeal, or high-threat message, will experience a greater change in intentions to perform testicular self-examinations than males exposed to an informative message, was not supported. This was predicted in accordance with the revised protection motivation theory, which states that fear heightens drive. In this case, the fear appeal condition reported greater intentions to engage in testicular self-examinations in all three intentions measures; however, the means were not statistically significant and cannot be correlated to an arousal of fear due to similar reports of fear in both conditions. Although the second manipulation check showed a statistically significant difference in the levels of fear arousal between conditions, the same did not occur during the actual experiment with larger numbers of participants. 


\section{Coping Appraisal Measures}

In Plotnikoff and Higginbotham's Basic Protection Motivation Theory Schema, the coping appraisal consists of two features: self-efficacy and response efficacy. A rise in either of these features will enhance a person's coping appraisal, thus making a person more likely to adapt the suggested behavior (or cease to engage in the maladaptive behavior) when the threat appraisal is equally high.

\section{Threat Appraisal Measures}

Plotnikoff and Higginbotham's Basic Protection Motivation Theory Schema states that the threat appraisal consists of two features: perceived vulnerability and perceived severity. A rise in either of these features will enhance a person's threat appraisal, thus making a person more likely to adapt the suggested behavior (or cease to engage in the maladaptive behavior).

Fear

There could be several explanations for the similarities in fear arousal for both conditions. First, the mere topic of testicular cancer may elicit feelings of fear and heightened arousal. It may not be the message inducing fear, but the topic, the disease itself. High marks were reported in the first and second measures of severity; therefore, it is clear that most participants had strong feelings about testicular cancer before a message was ever presented.

Similar results were reported by Muthuswamy \& Levine (2007) when they tested fear appeals on AIDS perceptions in Africa using the extended parallel processing model. The results revealed high pre-existing levels of fear about AIDS in participants. Therefore, the high-threat message had little impact on perceptions of fear and outcome 
measures of attitudes, intentions and behaviors. College males may already be fearful of testicular cancer; therefore, like the AIDS study, fear appeals are ineffective on audiences with high levels of pre-existing fear (Muthuswamy \& Levine, 2007).

Secondly, the subjectivity of the word "fear" should be taken into consideration. Men may have experienced heightened cognitive dissonance by these questions and messages, but may not classify these feelings as fearful feelings. Masculinity may also be taken into account here. Morman (2000) found that the more men approved of a traditional masculine gender role, the less positive their attitudes were toward testicular self-exams. Third, the messages may have needed to be refined and tested again until a greater amount of fear arousal was reported between the two conditions. Perhaps the fear appeal should have been re-designed a third time and tested in a manipulation check to have a greater effect on the fear condition.

Considering the fear appeal was moot in this case, perhaps the best place for implementing testicular self-examination behavior is pediatrician's and doctor's offices. As not to create fear but encourage TSE behaviors, self-exams should be encouraged at a young age so the behavior is commonplace once males reach the target age for developing the disease. If males are taught to look for testicular abnormalities in line with other preventative health behaviors, such as vaccines, they will know when a problem is present and be used to discussing testicular health with their physicians. Also, the argument can be made that middle and high school health classes should teach testicular self-examinations as a means of practical, preventative healthcare behavior. Since the self-examinations require discussion about a private area on the body, maybe fathers would be the most reliable teachers of self-exam behaviors when their sons are young. 


\section{Limitations}

While this research provides some insight into the use of fear appeals in protection motivation theory, there are several limitations that must be acknowledged. First, this study was conducted using two convenience samples from two college university classes; therefore, the results cannot be generalized across all males ages 15-35 who are most affected by testicular cancer. The male participants in this research represent a relatively small homogenous sample from a similar geographical location, and thus may have different attitudes, behaviors and views than a sample selected elsewhere. The experiment took place in West Virginia; although males from other states were presumably present in this sample, a large number of West Virginians were probably present as well. West Virginia ranks high in the following health categories compared to the rest of the United States: obesity rates, tobacco use and mortality by cancer. Based on this information, perhaps West Virginians are not an accurate population on which to test preventative health behavior theory. Also, the participants in this experiment were relatively young; $97 \%$ were between the ages of 18 and 23 . Therefore, this young age group may not have taken this study as seriously as an older cohort. Secondly, the study was conducted at the end of normally scheduled classes and participant focus and message processing may have been subsequently low. Third, the nature of experiments can be considered a weakness due to the artificial environment in which they take place. In a more comfortable, familiar setting, participants may feel better about sharing personal information about themselves. Fourth, although significantly different amounts of fear arousal (based on message) were reported during the final manipulation check, similar amounts of fear arousal were reported during the experiment. Thus, the true effect 
of the fear appeal was not tested. However, the similar amounts of fear arousal may be attributed to the subject of the survey, not the messages in question. Finally, all measures for this experiment were based on participant self-reporting; therefore, questions about attitudes and behaviors may have been answered in a socially acceptable manner and may not represent true attitudes and behaviors.

Many successful studies using the protection motivation theory (PMT) have focused on a particular group that engages in unhealthy behaviors (such as smoking, tanning, or having unprotected sex) and aims to cease these behaviors by using the four measures included in PMT. By targeting a group that already engages in threatening health behaviors, the threat may seem more imminent. In a study such as this one, the participants weren't being encouraged to cease an unhealthy behavior, but encouraged to begin performing a healthy behavior. As such, the participants in this study may have viewed testicular cancer as a random threat and not felt as personally at risk as, for example, a smoker may feel to lung cancer; therefore, PMT may not be applicable to engaging in healthful preventative acts.

\section{Implications}

This research might serve as a tool for health communication advocates and groups, namely the American Cancer Society, the Live Strong Foundation and the National Cancer Institute. Although the hypotheses were not supported, this opens up the subject of testicular cancer communication as a topic worthy of further exploration. It was apparent that both the conditions experienced a notable level of fear arousal; however, that fear seemed to come from their feelings about the disease itself and not the message in question. Therefore, alternative ways to successfully engage males about this subject 
are needed. Due to the uniqueness of this topic and these results, more research should be conducted concerning the best ways to increase college males' intentions to perform testicular self-examinations. Alternate theories and methods should be explored.

\section{Future Research}

There are several recommendations to keep in mind for performing similar protection motivation theory-based research. First, this experiment did not measure message processing. Noted by Umphrey (2003) as an important factor in message testing, message processing is defined as "the degree to which an individual pays careful attention to a message." Future research should measure participants' message processing, as it is an extraneous variable that could have a potential effect on experiment outcomes that was not tested in this case. Depth of message processing was measured by Umphrey (2003) by asking closed-ended questions relating to participants' motivation and ability and was shown to have an effect on outcome. If the participants in this case would have reported low levels of message processing, that could be the cause of the results; the participants could have simply not been paying attention. On the other hand, if high levels of message processing would have been reported in this case, we could conclude that the subject matter was the cause for such high levels of fear arousal in both conditions and future research could be crafted with this idea in mind. Also, participants may not want to acknowledge a change in their attitudes or intentions created by the message. This "macho factor" could be an underlying cause to the lack of difference noting in experimental outcomes.

In order to triangulate similar research and craft the most effective fearful message, a quasi-experiment, similar to that conducted by Houser, Burns \& Driver, could 
have tested four different fear-based messages. The message that evoked the greatest level of fear arousal in the initial quasi-experiment could have then been adapted into the main experiment model. This measure would assure that the fear-based message used in the experiment represented a true fear appeal. It would better ensure both the accuracy of the message and the validity of the experiment.

Future research should explore the effects of different types of threats concerning testicular cancer. For example, this research used the physical threat of death by testicular cancer as a means of motivation for self-examinations and the cause of fear arousal. Pechmann et al. (2003) examined different types of threats associated with smoking behaviors in adolescents. They found that social threats were the most likely cause of quitting smoking. With the inconclusive results obtained in this experiment, it is clear that research examining the effect of types of threats (i.e., emotional, psychological, social) on the particular audience in question is needed. Perhaps physical threats are not perceived as detrimental to this age group; a social threat of feeling like an outcast or psychological threat of feeling like less of man may be better motivators for college males.

Some PMT-based research measures the role of response cost in the likelihood that an individual will intend to adopt the health behaviors being presented (Lwin \& Saw, 2007). Response cost has a theoretically negative effect on the intentions, while increased perceived vulnerability, perceived severity, self-efficacy and response efficacy all have a positive effect on intentions. In this study, response cost was not taken into account because the cost of adopting testicular self-examination behaviors is extremely minimal. Regular testicular self-examination behavior would take less than five minutes of time, is 
done only once a month and can be done by oneself in the shower. This low cost of compliance was assumed to not be a deterrent in this case. Future testicular cancer research may test this extraneous measure to be sure it has no effect on the outcomes.

Another study designed similarly to this one should measure masculinity's effect on self-reporting fear questions, such as "Being fearful of testicular would make me feel like less of a man" and "Testicular cancer is a scary thought but I am not scared of it." These measures could shed some light as to why both groups reported similar amounts of fear arousal. It could be that many in this sample, college age males, are hesitant to admit they are scared or fearful. Other ways of measuring the subjective term of fear may change the outcomes of self-reporting.

To test the possible effect of pretesting on experimental outcomes, a Solomon four-group design should be utilized in future research examining PMT and testicular self-examination behaviors. The Solomon four-group design is a mix between the pretestposttest control group design and the posttest-only control group design that tests the effects of pretesting on outcomes by adding two groups more groups to the originial prepost test designs (Wimmer \& Dominick, 2006). In addition to the original two conditions- fear and no fear messages with a pre and posttest- two more experiments will be given to two more groups that consist of the two conditional messages with a posttest questionnaire only. In this experimental design, four conditions are present instead of the orginial two. This design would provide greater insight into the effect of pretest conditioning, check the efficacy of randomization and to detect any possible pretest manipulation interaction; however, this design does require four separate groups instead 
of two, which means more subjects, more time and more money (Wimmer \& Dominick, 2006).

Based on the results of this research, the case can be made that health communication models must be considered topic-specific. In this survey, bringing the subject of testicular cancer to participants' front of mind may have caused high levels of cognitive discomfort, thereby heightening levels of fear arousal before exposure and possibly making the messages under study obsolete. The nearly equal amount of fear arousal found in both post-test groups may be caused by the sensitive, emasculating, personal nature of the disease in question. With this in mind, future research should aim to elucidate the following questions: "What is an effective method of increasing college males' intentions of performing testicular self-examinations? What is the most effective communication theory used in this process?' By recognizing the ineffectiveness of a fear appeal on the subject of testicular cancer, better means of communicating about the need to perform testicular-self examinations is a topic that warrants future research. 


\section{Conclusion}

This research was done to explore the role of fear appeals in protection motivation theory and find messages that encourage males to perform testicular self-examinations. Although none of the proposed hypotheses were supported, an important point has indirectly surfaced: communication theories, especially those such as the protection motivation theory which include several subjective measures, should take into account the topic under study and nuances associated with particular topic. In this case, it was apparent that the males under study felt fearful of testicular cancer, felt that it was a severe disease and felt vulnerable to it. However, the minimal difference noted between fear arousal in the group through independent post-test T-tests shows that almost equal amounts of fear were aroused even before the message variable was introduced.

Therefore, a possible explanation could be that the mere topic of testicular cancer, not the messages under study, elicited high measures of fear arousal in the study sample and therefore, similar to the AIDS research conducted by Muthuswamy \& Levine (2007), the fear appeal was moot. 


\section{References}

Afifi, W., \& Weiner, J. (2004). Toward a theory of motivated information management. Communication Theory, 14, 167-190.

Ajzen, I., \& Fishbein, M. (1980). Understanding attitudes and predicting social behavior. Englewood Cliffs, NJ: Prentice Hall.

American Cancer Society. (2000). Cancer facts and figures-1999. Atlanta, GA: American Cancer Society.

American Cancer Society. (2007). Overview: Testicular cancer. Retrieved September 14, 2008, from http://www.cancer.org/docroot/CRI/CRI_2_1x.asp?dt=41.

Austoker, A. (1994). Cancer prevention in primary care: Screening for ovarian, prostatic, and testicular cancers. British Medical Journal, 309, 315-320.

Barling, N., \& Lehmann, M. (1999). Young men's awareness, attitudes and practice of testicular self-examination: A health action process approach. Psychology, Health \& Medicine, 4(3), 255-263.

Bender, H., Martin, I., \& Raish, C. (2006). What motivates homeowners to protect themselves from wildfire risks in the WUI. In Wildfires and fuels management: risk and human reaction.

Dillard, J.P., \& Anderson, J.W. (2004). The role of fear in persuasion. Psychology \& Marketing, 21(11), 909-926.

Dukeshire, S.R. (1996). Turning up the heat: the effects of fear appeals on sun-protective attitudes, intentions, and behaviours. Dissertation Abstracts International, 57(6-B), 4019B.

Folkman, S., Schafer, C., \& Lazarus, R. (1979). Cognitive Processes as Mediators of Stress and Coping," in Human Stress and Cognition. In V. Hamilton and D.M. Warburton (Eds.), Human Stress and Cognition: An Information Processing Approach. London: John Wiley and Sons, Inc.

Friestad, M., \& Thorson, E. (1985). The role of emotion in memory for television commercials. Paper presented at Mass Communications Division of the International Communication Association, Honolulu.

Gore, T., \& Bracken, C. (2004). Testing the theoretical design of a health risk message: reexamining the major tenets of the extended parallel process model. Health Education \& Behavior, 32(1), 27-41. 
Houser, M., Burns, M., \& Driver, N. (2007). Communicating with College Students about STIs: Assessing Message Effectiveness and Preferred Source and Channel. Human Communication, Vol. 10 Issue 3, p311-327.

Janis, I. (1967), "Effects of Fear Arousal on Attitude Change: Recent Developments in Theory and Experimental Research," in Advances in Experimental Social Psychology, Vol. 3. L. Berkowitz, ed. New York: Academic Press, Inc., 166-224.

Katz, R., Meyers, K., \& Walls, J. (1995). Cancer awareness and self-examination practices in young men and women. Journal of Behavioral Medicine, 18, 377-384

Laroche, M., Toffoli, R., Zhang, Q., \& Pons, F. (2001). A cross-cultural study of the persuasive effect of fear appeal messages in cigarette advertising: China and Canada. International Journal of Advertising, 20(3), pp 297-317.

Larose, R., Rifon, N., \& Wirth, C. (2007). Conference Papers. International Communication Association, 2007 Annual Meeting, p1-1, 1p

Lazarus, R. (1968). Emotions and Adaptation: Conceptual and Empirical Relations. Nebraska Symposium on Motivation, W. J. Arnold, ed. Lincoln: University of Nebraska Press, 175-266.

Lwin, M., \& Saw, S. (2007) Protection children from myopia: a PMT perspective for improving health marketing communications. Journal of Health Communication, 12:251268.

Maddux, J. \& Rogers, R. (1983), "Protection Motivation and Self-Efficacy: A Revised Theory of Fear Appeals and Attitude Change," Journal of Experimental Social Psychology, 19 (September), 469-79.

Moore, S., Barling, N. \& Hood, B. (1998). Predicting testicular and breast selfexamination behavior: A test of the theory of reasoned action. Behavior Change, 15(1), 41-49.

Morman, M. (2000). The influence of fear appeals, message design, and masculinity on men's motivation to perform the testicular self-exam. Journal of Applied Communication Research, 28(2), 91-116.

Muthuswamy, N., \& Levine, T. (2007). Scaring the already scared: some problems with HIV/AIDS fear appeals in Africa. Presented at the National Communication Association 2007, p1, 42 p.

National Cancer Institute. (2005). Testicular Cancer. Retrieved September 15, 2008, from http://www.cancer.gov/cancertopics/types/testicular. 
Peate, I. (1999). Testicular cancer: Helping to promote self-examination. Community Nurse, 32-33.

Pechmann, C. (2001). A comparison of health communication models: risk learning versus stereotype priming. Mediapsychology, 3, 189-210.

Pechmann, C., Zhao, G., Goldberg, M., \& Reibling, E. (2003). Journal of Marketing, Vol. 67 Issue 2, p1-18.

Lenth, R. V. (2006). Java Applets for Power and Sample Size [Computer software]. Retrieved November 11, 2008, from http://www.stat.uiowa.edu/ rlenth/Power.

Plotnikoff, R., \& Higginbotham, N. (2002). Protection Motivation Theory and exercise behavior change for the prevention of coronary heart disease in a high-risk, Australian representative community sample of adults. Psychology, Health, \& Medicine, 7(1), 8798.

Ray, M., \& Batra, R. (1983). Emotion and persuasion in advertising: what we do and don't know about affect. Advances in Consumer Research, 10, 543-8.

Rippetoe, P., \& Rogers, R. (1987). Effects of Components of Protection-Motivation Theory on Adaptive and Maladaptive Coping With a Health Threat. Journal of Personality and Social Psychology, 52 (March), 596-8.

Rogers, R. (1983). Cognitive and physiological processes in fear appeals and attitude change: a revised theory of protection motivation. In: Cacioppo, C. \& Petty, R. (Eds), Social psychology: a sourcebook (pp. 153-176). New York: Guilford Press.

Rogers, R. W. (1975). A protection motivation theory of fear appeals and attitude change. Journal of Psychology, 91, 93-114.

Steadman, L., \& Quine, L. (2004). Encouraging young males to perform testicular selfexamination: A simple, but effective, implementation intentions intervention. British Journal of Health Psychology, 9, 479-487.

Tanner, J., Hunt, B., \& Eppright, D. (1991). A protection motivation model: a normative model of fear appeals. Journal of Marketing, 55, 36-45.

Testicular Cancer Resource Center. (2007). How to do a testicular self-examination. Retrieved April 11, 2008, from http://www.acor.org/TCRC/tcexam.html.

Umphrey, L. (2001). The effects of message framing and message processing on testicular self-examination and perceived susceptibility. Communication Research Reports, 20(2), 97-105.

Wimmer, R. D., \& Dominick, J. R. (2006). Mass media research: an introduction. Belmont, CA: Thomson Wadsworth. 
Witte, K. (1994). Fear control and danger control: A test of extended parallel process model (EPPM). Communication Monographs, 61, 113-135.

Youn, S. (2005). Teenagers' perceptions of online privacy and coping behaviors: A risk/benefit appraisal approach. Journal of Broadcasting \& Electronic Media, 49, 86-110. 


\title{
Appendix A
}

\section{IRB Approval Letter}

The research study referenced above was reviewed by The West Virginia University Board for expedited review on 1/29/2009; on 01/30/2009, Anne Swisher approved this study via expedited review procedures.

\section{Expedited - IRB Protocol - Approval}

\author{
To: $\quad$ Martinelli, Diana \\ From: $\quad$ WVU Office of Research Compliance \\ Date: $\quad$ Friday, January 30, 2009 \\ Subject: No action required \\ \#: $\quad \mathrm{H}-21456$ \\ Title: $\quad$ Encouraging Testicular Self-Examination Behaviors in College Males: \\ Examining the Role of Fear Appeals in Potection Motivation Theory
}

While no action is required on your part, the IRB made the following findings:

This protocol was reviewed using the following:

Expedited Review Checklist (210a)

Informed Consent - Only Minimal Risk Checklist (210z)

The following documents have been approved and validated for use in this study and are available in the BRAAN system:

Consent Form

Thank you.

Board Designee: White, Barbara Letter Sent By:

White, Barbara, 1/30/2009 9:28 AM 
Once you begin your human subject research the following regulations apply:

1. Unanticipated or serious adverse events/side effects encountered in this research study must be reported to the IRB within five (5) days.

2. Any modifications to the study protocol or informed consent form must be reviewed and approved by the IRB prior to implementation.

3. You may not use a modified informed consent form until it has been approved and validated by the IRB. 


\section{Appendix B}

\section{P.I. Reed School of Journalism Extra Credit Plan for Student Research Participation}

May 10, 2007

Please note that extra credit for participation will be offered only in those instances where it is deemed necessary to help gain the numbers or types of students for valid results and in those courses where a set standard grading scale is used to assign final grades (e.g. 90-100\% of total points $=$ A). In other words, professors who teach classes in which final grades are assigned on a curve should not allow extra credit points for research participation. To do so unfairly penalizes those students who cannot or who choose not to participate in extra credit activities.

\section{Procedures}

Students are told about extra credit opportunities through their professors, who have agreed to allow extra credit for participation. Students may be asked to participate during class or to attend a session outside of the classroom on their own time (e.g. in the case of controlled experimental research, where students are exposed to various types of advertising or public service messages and asked to respond to those).

\section{External locations}

For extra credit outside of class time, students are asked to "sign in" when they arrive at a lab or log on to the Web using their own computer or the one provided by the experimenter. This is the only way their names are known, and their names are not associated with any of the experimental responses. For studies that need exposure to multiple experimental sessions, student names may need to be associated with their responses for tracking purpose only. All personally identifying information will be promptly disposed upon data analyses. Of course, all procedures will have been submitted to and approved by the IRB.

\section{Classroom participation}

In classroom settings, where professors have approved the extra credit offering, students turn in their responses (e.g. to an anonymous survey that has ) and are asked to sign a separate sheet on the other side of the room after doing so. Again, all personally identifying information will be properly disposed after data analyses, and all procedures will have been submitted to and approved by the IRB.

Points allowed

Extra credit will range from 0.5 to 2 percent of the maximum point total a student can earn in a class, depending on the participating professor's desire and the time the participant is expected to spend. 


\section{P.I. Reed School of Journalism Extra Credit Plan for Student Research Participation}

Page 2

\section{Alternative assignments}

Students who choose not to participate in the research must be offered alternative forms of extra credit by their participating professors. This will be communicated to each professor who agrees to allow their students extra credit to participate in the research and will be communicated to the students when the research opportunity arises. (In addition, once the IRB has approved the School of Journalism extra credit plan for research participation, all SOJ faculty, including adjuncts, will be given a copy of the policy.)

The options for extra credit must be equivalent to the points awarded for participation in the research and to the amount of time, thought, and effort required of it. Professors will be given the following as alternative extra credit options:

- having students seek out and view a particular type of ad (magazine, TV, radio, Internet, newspaper) and answer basic questions that are relevant to issues being studied (e.g., target audience, design/image elements, message components, appeal types ....)

- having students seek out and view or read a particular news article or story in two different media outlets and compare / contrast them in terms of topics being studied and discussed in class

- having students use existing WVU databases (e.g. Mediamark) to learn about a particular audience, mass medium, product line or brand

- having students develop a limited annotated bibliography on a particular course subject of interest to the student and the professor

- having students submit a one or two-page summary of a relevant journal article

- having students attend a guest speaker or lecture that is being hosted by the School or by some other University department on a topic relevant to the course and writing a one-page paper on what the student learned relevant to the course or the profession. 


\section{Appendix C}

\section{CONSENT AND INFORMATION FORM}

OMR ICF

Principal Investigator: Martinelli, Diana

Department: Journalism Tracking

Number: H-21456

\section{Study Title:}

Encouraging Testicular Self-Examination Behaviors in College Males:

Examining the Role of Fear Appeals in Potection Motivation Theory

Co-Investigator(s):

Slider, Cara

\section{Contact Persons}

If you have any questions, concerns, or complaints about this research, you can contact Cara Slider, BSJ at 304-293-3505 ext. 5442.

For information regarding your rights as a research subject, you may contact the Office of Research Compliance at 304/293-7073.

\section{Introduction}

You, , have been asked to participate in this research study, which has been explained to you by . This study is being conducted by Cara Slider, BSJ and Diana Martinelli, MS , PhD in the Department of J ournalism at West Virginia University. This research is being conducted to fulfill the requirements for a master's thesis in J ournalism in the Department of Journalism at West Virginia University, under the supervision of Dr. Diana Martinelli. 
Tracking \#: H-21456

\section{Purposes of the Study}

The purpose of this study is to learn more about the impact designed messages have on intentions to perform certain preventative health behaviors. WVU expects to enroll approximately 130 subjects.

\section{Description of Procedures}

This study involves filling out a questionnaire that measures health knowledge two times: both before and after viewing a message about preventative health behaviors. You do not have to answer all the questions. You will have the opportunity to see the questionnaire before signing this consent form. You will be randomly assigned (have an equal chance of being assigned like flipping a coin) to view one of two messages about preventative health behavior, but you will not know which message you receive. Overall, the entire study will takeapproximately 15 minutes ( 5 minutes to fill out each questionnaire and 5 minutes to view the health message).

\section{Risks and Discomforts}

There are no known or expected risks from participating in this study, except for the mild frustration associated with answering the questions.

\section{Alternatives}

You do not have to participate in this study.

There are no other alternatives at the present time.

\section{Benefits}

You may receive the direct benefit of learning more about certain health issues and how to accurately perform a preventative health care measure. The knowledge gained from this study may eventually benefit others.

\section{Financial Considerations}

There are no special fees for participating in this study, but extra credit points will be awarded for this class. There will be other extra credit opportunities available during this semester. 


\section{Confidentiality}

Any information about you that is obtained as a result of your participation in this research will be kept as confidential as legally possible. Your research records and test results, just like hospital records, may be subpoenaed by court order or may be inspected by federal regulatory authorities without your additional consent. In addition, there are certain instances where the researcher is legally required to give information to the appropriate authorities. These would include mandatory reporting of infectious diseases, mandatory reporting of information about behavior that is imminently dangerous to you or to others, such as suicide, child abuse, etc. In any publications that result from this research, neither your name nor any information from which you might be identified will be published without your consent.

\section{Voluntary Participation}

Participation in this study is voluntary. You are free to withdraw your consent to participate in this study at any time. Refusal to participate or withdrawal will not affect your future care, [or your employee status at West Virginia University or your class standing or grades, as appropriate] and will involve no penalty to you. In the event new information becomes available that may affect your willingness to participate in this study, this information will be given to you so that you can make an informed decision about whether or not to continue your participation. You have been given the opportunity to ask questions about the research, and you have received answers concerning areas you did not understand. 
Tracking \#: H-21456

Upon signing this form, you will receive a copy. I

willingly consent to participate in this research.

Signature of Subject or Printed Name Date Time Subjects Legal Representative

The participant has had the opportunity to have questions addressed. The participant willingly agrees to be in the study.

Signature of Investigator or Printed Name Date Time Co-Investigator 


\section{Appendix D, Manipulation Check \#1}

(Questions have been adapted from an earlier study conducted by Bender et al., 2006)

\section{Please circle your answer to the following questions. Please choose only one answer to each question.}

1. Are you a male between the ages of $18-35$ ?

Yes No

*If no, you do not meet the age requirement for this experiment. Thank you for your participation; there is no need to continue this survey.

2. Does testicular cancer affect males your age?
Yes
No
Don’t Know

3. Have you ever performed a testicular self-examination (examined your testicles for abnormalities, lumps, or swelling)?
Yes
No
Don’t Know

4. Have you personally ever known anyone who had/has testicular cancer?
Yes
No
Don’t Know

5. If you answered yes to the previous question, what was the nature of your acquaintance with the person having testicular cancer?

Brother Father Friend Cousin Son Uncle Other

(Prior knowledge/experience) 
On a scale of 1 to 7, with 1 indicating strong disagreement and 7 indicating strong agreement, circle a number to represent how much you agree or disagree with the following statements:

6. Developing testicular cancer would be one of the worst things that could happen to me.

$\begin{array}{ccccccc}1 & 2 & 3 & 4 & 5 & 6 & \begin{array}{c}7 \\ \text { strongly } \\ \text { strongly } \\ \text { disagree }\end{array}\end{array}$

7. The impact of testicular cancer would be severe on someone my age.

$\begin{array}{ccccccc}1 & 2 & 3 & 4 & 5 & 6 & \begin{array}{c}7 \\ \text { strongly } \\ \text { agree } \\ \text { disagree }\end{array}\end{array}$

8. The negative aspects of testicular cancer feel serious to me personally.

$\begin{array}{ccccccc}1 & 2 & 3 & 4 & 5 & 6 & \begin{array}{c}7 \\ \text { strongly } \\ \text { agree } \\ \text { disagree }\end{array}\end{array}$

(Perceived severity)

9. It is likely that testicular cancer will affect me personally.

$\begin{array}{ccccccc}1 & 2 & 3 & 4 & 5 & 6 & \begin{array}{c}7 \\ \text { strongly } \\ \text { agree } \\ \text { disagree }\end{array}\end{array}$

10. I feel vulnerable to the possibility of testicular cancer affecting me personally.

$\begin{array}{ccccccc}1 & 2 & 3 & 4 & 5 & 6 & \begin{array}{c}7 \\ \text { strongly } \\ \text { agree } \\ \text { disagree }\end{array}\end{array}$

(Perceived vulnerability)

11. Performing testicular self-examinations (TSE) will reduce the risk of testicular cancer affecting my life negatively. 


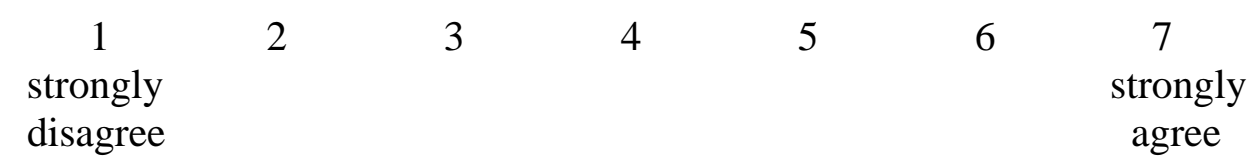

12. I feel that testicular self-examinations (TSE) are effective at discovering testicular cancer at an early stage.

$\begin{array}{ccccccc}1 & 2 & 3 & 4 & 5 & 6 & \begin{array}{c}7 \\ \text { strongly } \\ \text { agree } \\ \text { disagree }\end{array}\end{array}$

(Response Efficacy)

13. I feel confident in my ability to perform a testicular self-examination.

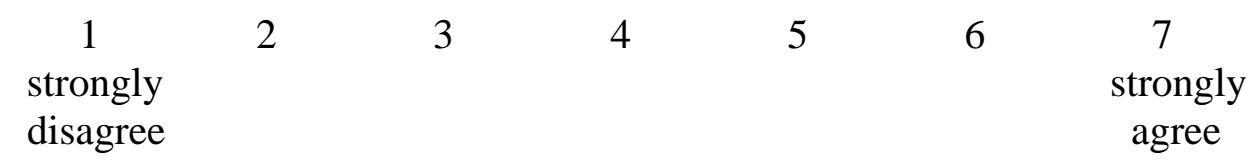

14. I am capable of accurately performing a testicular self-examination.

$\begin{array}{ccccccc}1 & 2 & 3 & 4 & 5 & 6 & \begin{array}{c}7 \\ \text { strongly } \\ \text { agree }\end{array} \\ \text { disagree } & & & & & & \end{array}$

(Self-Efficacy)

15. I already perform testicular self-examinations.

$\begin{array}{ccccccc}1 & 2 & 3 & 4 & 5 & 6 & \begin{array}{c}7 \\ \text { strongly } \\ \text { agree } \\ \text { disagree }\end{array}\end{array}$

16. It is likely that I will perform a testicular self-examination (TSE) at least once in the next 6 months.

$\begin{array}{ccccccc}1 & 2 & 3 & 4 & 5 & 6 & 7 \\ \begin{array}{c}\text { strongly } \\ \text { disagree }\end{array} & & & & & & \begin{array}{c}\text { strongly } \\ \text { agree }\end{array}\end{array}$


17. I plan to perform testicular self-examinations regularly (once a month) in the next 6 months.

$\begin{array}{ccccccc}1 & 2 & 3 & 4 & 5 & 6 & \begin{array}{c}7 \\ \text { strongly } \\ \text { agree } \\ \text { disagree }\end{array}\end{array}$

18. I intend to perform testicular self-examinations regularly in the next 6 months.

$\begin{array}{ccccccc}1 & 2 & 3 & 4 & 5 & 6 & \begin{array}{c}7 \\ \text { strongly } \\ \text { agree } \\ \text { disagree }\end{array}\end{array}$

(Intentions)

Please read carefully the following message. 


\section{(Fear message)}

\section{Please read carefully the following message}

\section{American Cancer Society wants you to know....}

You are in the prime age group for developing testicular cancer. Testicular cancer usually presents itself as a painless lump in one or both testes. It is the most common cancer and a leading cause of death for young males. When found early, testicular cancer holds a 96\% survival rate. We recommend a simple testicular self-examination to notice changes or discomfort in the scrotal area. If you find a lump or area of concern on the scrotum, a doctor should be notified immediately. Remember, early detection will increase your likelihood of survival!

The Testicular Cancer Resource Center (TCRC.com) recommends following these steps every month (keep in mind that the point is not to find something wrong, it is to learn what everything feels like so that you will know if something changes):

- Stand in front of a mirror. Check for any swelling on the scrotal skin.

- Examine each testicle with both hands. Place the index and middle fingers under the testicle with the thumbs placed on top. Roll the testicle gently between the thumbs and fingers -- you shouldn't feel any pain when doing the exam. Don't be alarmed if one testicle seems slightly larger than the other, that's normal.

- Find the epididymis, the soft, tubelike structure behind the testicle that collects and carries sperm. If you are familiar with this structure, you won't mistake it for a suspicious lump. Cancerous lumps usually are found on the sides of the testicle but can also show up on the front. Lumps on the epididymis are not cancerous.

- If you find a lump on your testicle, see a doctor, preferably a urologist, right away. The abnormality may not be cancer; it may just be an infection. But if it is testicular cancer, it will spread if it is not stopped by treatment. Waiting and hoping will not fix anything. Please note that free floating lumps in the scrotum that are not attached in any way to a testicle are not testicular cancer. When in doubt, get it checked out - if only for peace of mind!

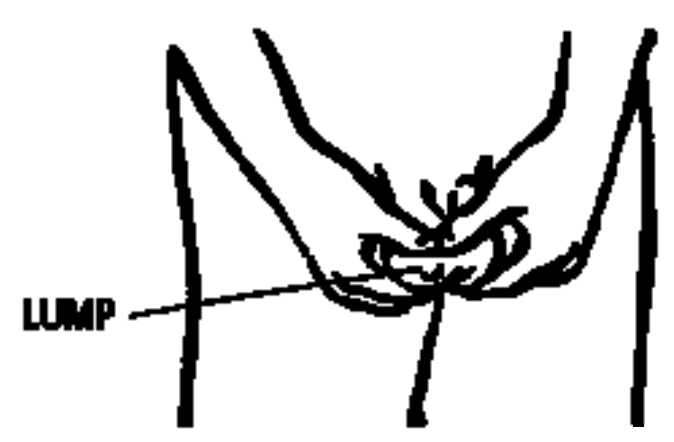




\section{(Informational Message)}

\section{Please read carefully the following message}

\section{American Cancer Society wants you to know....}

Testicular cancer is the most common cancer found in men between the ages of 15 and 35 . Testicular cancer usually presents itself as a painless lump in one or both testes. When found early, testicular cancer holds a $96 \%$ survival rate. We recommend a simple testicular selfexamination to notice changes or discomfort in the scrotal area. If you find a lump or area of concern on the scrotum, a doctor should be notified immediately.

The Testicular Cancer Resource Center (TCRC.com) recommends following these steps every month (keep in mind that the point is not to find something wrong, it is to learn what everything feels like so that you will know if something changes):

- $\quad$ Stand in front of a mirror. Check for any swelling on the scrotal skin.

- Examine each testicle with both hands. Place the index and middle fingers under the testicle with the thumbs placed on top. Roll the testicle gently between the thumbs and fingers -- you shouldn't feel any pain when doing the exam. Don't be alarmed if one testicle seems slightly larger than the other, that's normal.

- Find the epididymis, the soft, tubelike structure behind the testicle that collects and carries sperm. If you are familiar with this structure, you won't mistake it for a suspicious lump. Cancerous lumps usually are found on the sides of the testicle but can also show up on the front. Lumps on the epididymis are not cancerous.

- If you find a lump on your testicle, see a doctor, preferably an urologist, right away. The abnormality may not be cancer; it may just be an infection. But if it is testicular cancer, it will spread if it is not stopped by treatment. Waiting and hoping will not fix anything. Please note that free floating lumps in the scrotum that are not attached in any way to a testicle are not testicular cancer. When in doubt, get it checked out - if only for peace of mind!

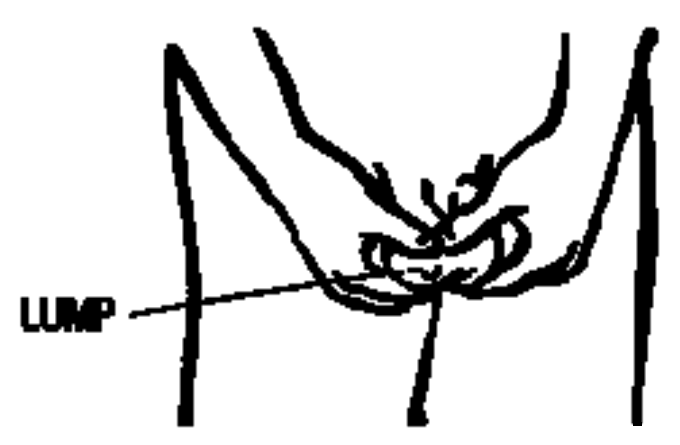


On a scale of 1 to 7 , with 1 indicating strong disagreement and 7 indicating strong agreement, circle a number to represent how much you agree or disagree with the following statements:

1. Developing testicular cancer would be one of the worst things that could happen to me.

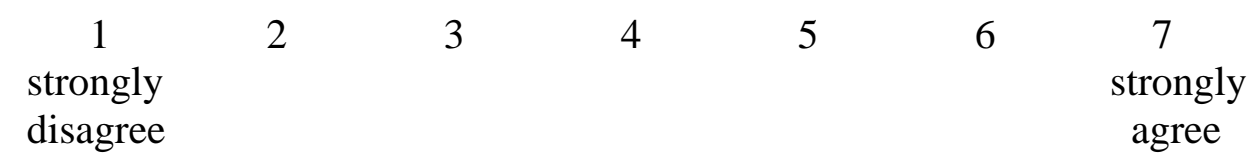

2. The impact of testicular cancer would be severe on someone my age.

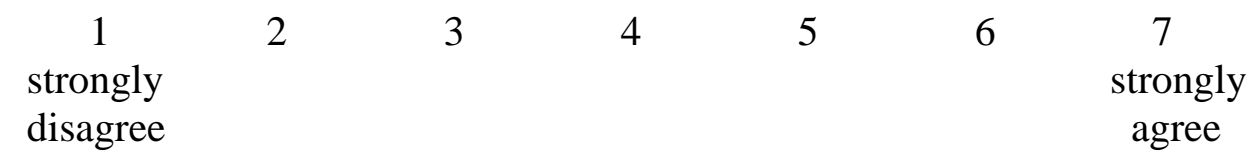

3. The negative aspects of testicular cancer feel serious to me personally.

$\begin{array}{ccccccc}1 & 2 & 3 & 4 & 5 & 6 & \begin{array}{c}7 \\ \text { strongly } \\ \text { agree } \\ \text { disagree }\end{array}\end{array}$

(Perceived severity)

4. It is likely that testicular cancer will affect me personally.

$\begin{array}{ccccccc}1 & 2 & 3 & 4 & 5 & 6 & \begin{array}{c}7 \\ \text { strongly } \\ \text { agree } \\ \text { disagree }\end{array}\end{array}$

5. I feel vulnerable to the possibility of testicular cancer affecting me personally.

$\begin{array}{ccccccc}1 & 2 & 3 & 4 & 5 & 6 & \begin{array}{c}7 \\ \text { strongly } \\ \text { agree } \\ \text { disagree }\end{array}\end{array}$

(Perceived vulnerability) 
6. Performing testicular self-examinations (TSE) will reduce the risk of testicular cancer affecting my life negatively.

$\begin{array}{ccccccc}1 & 2 & 3 & 4 & 5 & 6 & \begin{array}{c}7 \\ \text { strongly } \\ \text { strongly } \\ \text { disagree }\end{array}\end{array}$

7. I feel that testicular self-examinations (TSE) are effective at discovering testicular cancer at an early stage.

$\begin{array}{ccccccc}1 & 2 & 3 & 4 & 5 & 6 & \begin{array}{c}7 \\ \text { strongly } \\ \text { agree } \\ \text { disagree }\end{array}\end{array}$

(Response Efficacy)

8. I feel confident in my ability to perform a testicular self-examination.

$\begin{array}{ccccccc}1 & 2 & 3 & 4 & 5 & 6 & \begin{array}{c}7 \\ \text { strongly } \\ \text { agree } \\ \text { disagree }\end{array}\end{array}$

9. I am capable of accurately performing a testicular self-examination.

$\begin{array}{ccccccc}1 & 2 & 3 & 4 & 5 & 6 & \begin{array}{c}7 \\ \text { strongly } \\ \text { agree } \\ \text { disagree }\end{array}\end{array}$

(Self-Efficacy)

10. I already perform testicular self-examinations.

$\begin{array}{ccccccc}1 & 2 & 3 & 4 & 5 & 6 & \begin{array}{c}7 \\ \text { strongly } \\ \text { strongly } \\ \text { disagree }\end{array}\end{array}$

11. It is likely that I will perform a testicular self-examination (TSE) at least once in the next 6 months.

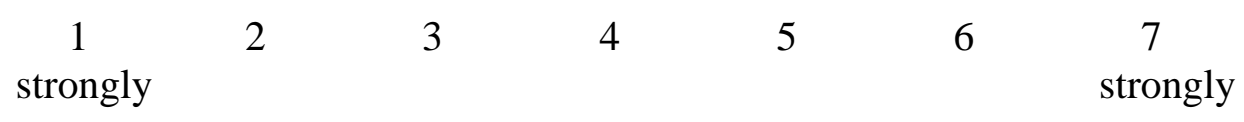


12. I plan to perform testicular self-examinations regularly (once a month) in the next 6 months.

$\begin{array}{ccccccc}1 & 2 & 3 & 4 & 5 & 6 & \begin{array}{c}7 \\ \text { strongly } \\ \text { agree } \\ \text { disagree }\end{array}\end{array}$

13. I intend to perform testicular self-examinations regularly in the next 6 months.

$\begin{array}{ccccccc}1 & 2 & 3 & 4 & 5 & 6 & \begin{array}{c}7 \\ \text { strongly } \\ \text { agree } \\ \text { disagree }\end{array}\end{array}$

(Intentions)

14. The message I read made me feel fearful of testicular cancer.

$\begin{array}{ccccccc}1 & 2 & 3 & 4 & 5 & 6 & \begin{array}{c}7 \\ \text { strongly } \\ \text { agree } \\ \text { disagree }\end{array}\end{array}$

15. The message I read makes me feel fearful about testicular cancer affecting me.

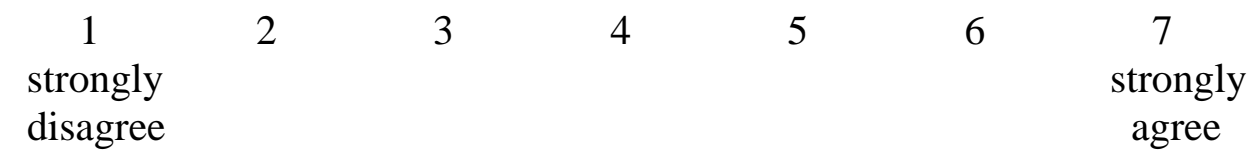

16. I feel frightened about the subject of testicular cancer.

$\begin{array}{ccccccc}1 & 2 & 3 & 4 & 5 & 6 & \begin{array}{c}7 \\ \text { strongly } \\ \text { agree } \\ \text { disagree }\end{array}\end{array}$

(Fear)

17. In which age group do you belong?

$$
\text { 18-20 21-23 24-26 27-29 } 30 \text { \& up }
$$

18. In to which student rank do you fall? 
Freshman Sophomore Junior Senior Graduate

19. Of what ethnicity do you consider yourself?

Caucasian African American Asian Latino Other

(Demographics) 
Appendix E, Manipulation Check \#2

Please circle your answer to the following questions. Please choose only one answer to each question. If you find a question to be confusing or misleading, please circle that question and make a note beside it explaining the problem. This is a pretest to ensure that the following questions are clear, precise and easy to answer. Your feedback will ensure a successful experiment.

1. Are you a male between the ages of 18-35?

Yes No

*If no, you do not meet the age requirement for this experiment. Thank you for your participation; there is no need to continue this survey.

2. Does testicular cancer affect males your age?
Yes
No
Don’t Know

3. Have you ever performed a testicular self-examination (examined your testicles for abnormalities, lumps, or swelling)?
Yes
No
Don’t Know

4. Have you personally ever known anyone who had/has testicular cancer?
Yes
No
Don’t Know

5. If you answered yes to the previous question, what was the nature of your acquaintance with the person having testicular cancer?

Brother Father Friend Cousin Son Uncle Other 
On a scale of 1 to 7 , with 1 indicating strong disagreement and 7 indicating strong agreement, circle a number to represent how much you agree or disagree with the following statements:

6. Developing testicular cancer would be one of the worst things that could happen to me.

$\begin{array}{ccccccc}1 & 2 & 3 & 4 & 5 & 6 & \begin{array}{c}7 \\ \text { strongly } \\ \text { agree } \\ \text { disagree }\end{array}\end{array}$

7. The negative aspects of testicular cancer feel serious to me.

$\begin{array}{ccccccc}1 & 2 & 3 & 4 & 5 & 6 & \begin{array}{c}7 \\ \text { strongly } \\ \text { agree } \\ \text { disagree }\end{array}\end{array}$

8. It is likely that testicular cancer will affect me.

$\begin{array}{ccccccc}1 & 2 & 3 & 4 & 5 & 6 & \begin{array}{c}7 \\ \text { strongly } \\ \text { agree } \\ \text { disagree }\end{array}\end{array}$

9. Performing testicular self-examinations (TSE) will reduce the risk of testicular cancer affecting my life negatively.

$\begin{array}{ccccccc}1 & 2 & 3 & 4 & 5 & 6 & \begin{array}{c}7 \\ \text { strongly } \\ \text { agree } \\ \text { disagree }\end{array}\end{array}$

10. I feel that testicular self-examinations (TSE) are effective at discovering testicular cancer at an early stage.

$\begin{array}{ccccccc}1 & 2 & 3 & 4 & 5 & 6 & \begin{array}{c}7 \\ \text { strongly } \\ \text { agree } \\ \text { disagree }\end{array}\end{array}$


11. I feel confident in my ability to perform a testicular self-examination.

$\begin{array}{ccccccc}1 & 2 & 3 & 4 & 5 & 6 & \begin{array}{c}7 \\ \text { strongly } \\ \text { agree } \\ \text { disagree }\end{array} \\ \end{array}$

12. I am capable of accurately performing a testicular self-examination.

$\begin{array}{ccccccc}1 & 2 & 3 & 4 & 5 & 6 & \begin{array}{c}7 \\ \text { strongly } \\ \text { agree } \\ \text { disagree }\end{array}\end{array}$

13. I already perform testicular self-examinations.

$\begin{array}{ccccccc}1 & 2 & 3 & 4 & 5 & 6 & \begin{array}{c}7 \\ \text { strongly } \\ \text { agree } \\ \text { disagree }\end{array}\end{array}$

14. I intend to perform TSE regularly in the next 6 months.

\begin{tabular}{|c|c|c|c|c|c|c|}
\hline $\begin{array}{c}1 \\
\text { strongly } \\
\text { disagree }\end{array}$ & 2 & & 4 & 5 & $\epsilon$ & $\begin{array}{c}7 \\
\text { strongly } \\
\text { agree }\end{array}$ \\
\hline
\end{tabular}

15. It is likely that I will perform a testicular self-examination TSE at least once in the next 6 months.

$\begin{array}{ccccccc}1 & 2 & 3 & 4 & 5 & 6 & \begin{array}{c}7 \\ \text { strongly } \\ \text { agree } \\ \text { disagree }\end{array}\end{array}$

16. I plan to perform TSE regularly (once a month) in the next 6 months.

$\begin{array}{ccccccc}1 & 2 & 3 & 4 & 5 & 6 & 7 \\ \begin{array}{c}\text { strongly } \\ \text { disagree }\end{array} & & & & & & \begin{array}{c}\text { strongly } \\ \text { agree }\end{array}\end{array}$

Please read thoroughly the entire following message 


\section{Please read carefully the following message}

\section{American Cancer Society wants you to know....}

You are in the prime age group for developing testicular cancer. It is the most common cancer and a leading cause of death for males your age. A simple testicular self-examination is encouraged to notice changes or discomfort in the scrotal area. A cancerous lump is most often found by performing a testicular self-examination. Remember, early detection will lessen your chance of death!

The Testicular Cancer Resource Center (TCRC.com) recommends following these steps every month:

- Stand in front of a mirror. Check for any swelling on the scrotal skin.

- Examine each testicle with both hands. Place the index and middle fingers under the testicle with the thumbs placed on top. Roll the testicle gently between the thumbs and fingers -- you shouldn't feel any pain when doing the exam.

- Find the epididymis, the soft, tubelike structure behind the testicle that collects and carries sperm. If you are familiar with this structure, you won't mistake it for a suspicious lump. Cancerous lumps usually are found on the sides of the testicle but can also show up on the front.

- If you find a lump on your testicle, see a doctor, preferably a urologist, right away. If it is testicular cancer, it will spread if it is not stopped by treatment. Waiting and hoping will not fix anything. Get any lumps checked by a doctor.

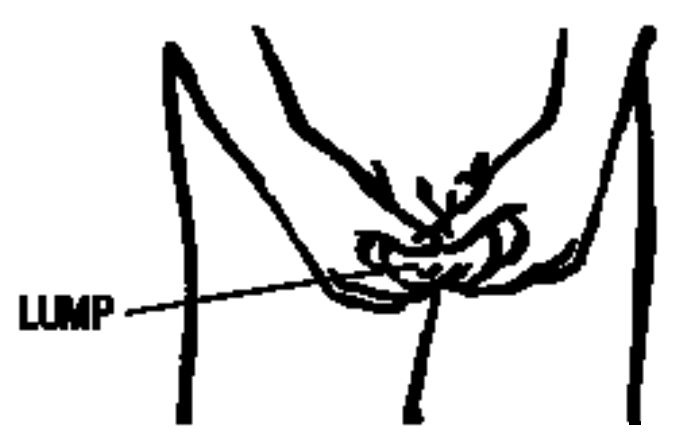

Your life could depend on it. 


\section{Please read carefully the following message}

\section{American Cancer Society wants you to know....}

Testicular cancer is the most common cancer found in men between the ages of 15 and 35 . Testicular cancer usually presents itself as a painless lump in one or both testes. When found early, testicular cancer holds a 96\% survival rate. A simple testicular self-examination is encouraged to notice changes or discomfort in the scrotal area. If you find a lump or area of concern on the scrotum, a doctor should be notified immediately.

The Testicular Cancer Resource Center (TCRC.com) recommends following these steps every month:

- Stand in front of a mirror. Check for any swelling on the scrotal skin.

- Examine each testicle with both hands. Place the index and middle fingers under the testicle with the thumbs placed on top. Roll the testicle gently between the thumbs and fingers -- you shouldn't feel any pain when doing the exam.

- Find the epididymis, the soft, tubelike structure behind the testicle that collects and carries sperm. If you are familiar with this structure, you won't mistake it for a suspicious lump. Cancerous lumps usually are found on the sides of the testicle but can also show up on the front.

- If you find a lump on your testicle, see a doctor, preferably an urologist. The abnormality may not be cancer; it may just be an infection. When in doubt, get it checked out - if only for peace of mind.

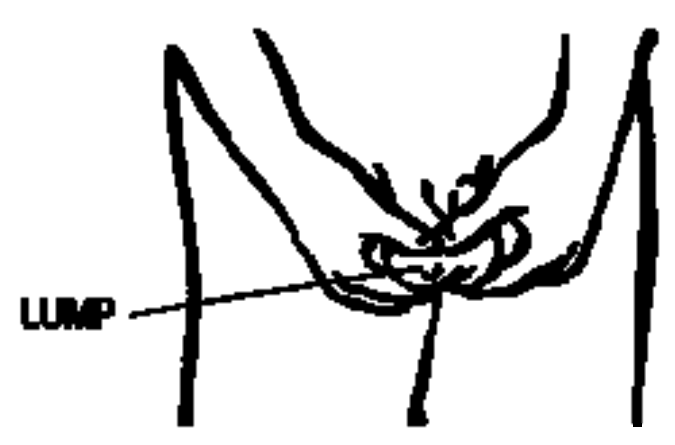


On a scale of 1 to 7 , with 1 indicating strong disagreement and 7 indicating strong agreement, circle a number to represent how much you agree or disagree with the following statements:

1. Developing testicular cancer would be one of the worst things that could happen to me.

$\begin{array}{ccccccc}1 & 2 & 3 & 4 & 5 & 6 & \begin{array}{c}7 \\ \text { strongly } \\ \text { strongly } \\ \text { disagree }\end{array}\end{array}$

2. The negative aspects of testicular cancer feel serious to me.

$\begin{array}{ccccccc}1 & 2 & 3 & 4 & 5 & 6 & \begin{array}{c}7 \\ \text { strongly } \\ \text { agree } \\ \text { disagree }\end{array}\end{array}$

3. It is likely that testicular cancer will affect me.

$\begin{array}{ccccccc}1 & 2 & 3 & 4 & 5 & 6 & \begin{array}{c}7 \\ \text { strongly } \\ \text { agree } \\ \text { disagree }\end{array}\end{array}$

4. Performing testicular self-examinations (TSE) will reduce the risk of testicular cancer affecting my life negatively.

$\begin{array}{ccccccc}1 & 2 & 3 & 4 & 5 & 6 & \begin{array}{c}7 \\ \text { strongly } \\ \text { agree } \\ \text { disagree }\end{array}\end{array}$

5. I feel that testicular self-examinations (TSE) are effective at discovering testicular cancer at an early stage.

$\begin{array}{ccccccc}1 & 2 & 3 & 4 & 5 & 6 & \begin{array}{c}7 \\ \text { strongly } \\ \text { agree } \\ \text { disagree }\end{array}\end{array}$


6. I feel confident in my ability to perform a testicular self-examination.

$\begin{array}{ccccccc}1 & 2 & 3 & 4 & 5 & 6 & \begin{array}{c}7 \\ \text { strongly } \\ \text { agree }\end{array} \\ \text { disagree } & & & & & & \end{array}$

7. I am capable of accurately performing a testicular self-examination.

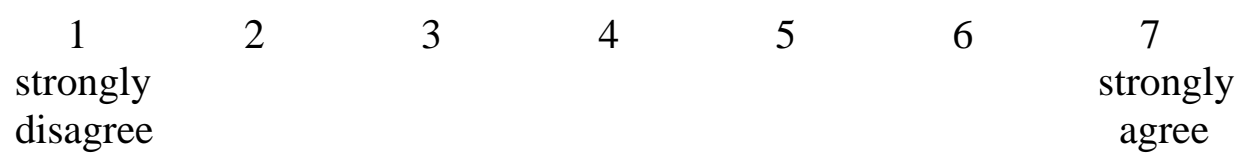

8. I already perform testicular self-examinations.

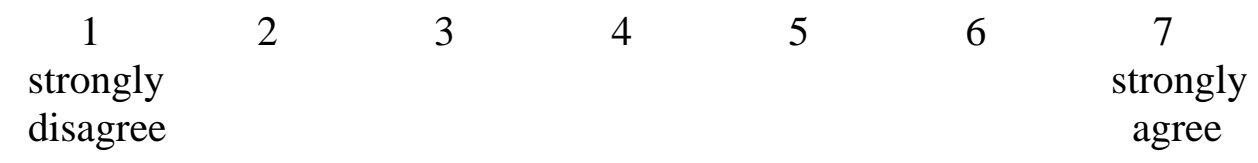

9. I intend to perform TSE regularly in the next 6 months.

\begin{tabular}{|c|c|c|c|c|c|}
\hline $\begin{array}{c}1 \\
\text { strongly } \\
\text { disagree }\end{array}$ & 2 & 3 & 4 & 5 & 6 \\
\hline
\end{tabular}

10. It is likely that I will perform a testicular self-examination TSE at least once in the next 6 months.

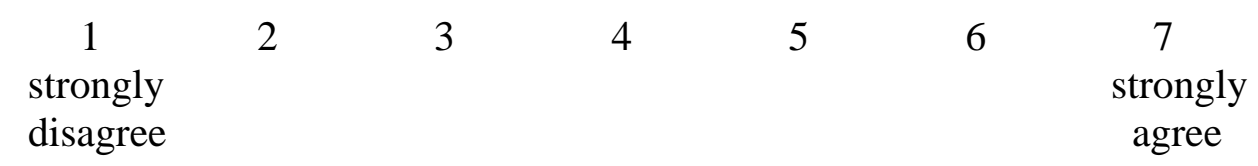

11. I plan to perform TSE regularly (once a month) in the next 6 months.

$\begin{array}{cccccccc}1 & 2 & 3 & 4 & 5 & 6 & \begin{array}{c}7 \\ \text { strongly } \\ \text { agree }\end{array} \\ \text { disagree } & & & & & & & \end{array}$


12. The message I read made me feel fearful of testicular cancer.

$\begin{array}{ccccccc}1 & 2 & 3 & 4 & 5 & 6 & \begin{array}{c}7 \\ \text { strongly } \\ \text { agree } \\ \text { disagree }\end{array}\end{array}$

13. The message I read makes me feel fearful about testicular cancer affecting me.

$\begin{array}{ccccccc}1 & 2 & 3 & 4 & 5 & 6 & \begin{array}{c}7 \\ \text { strongly } \\ \text { agree } \\ \text { disagree }\end{array}\end{array}$

14. I feel frightened about the subject of testicular cancer.

$\begin{array}{ccccccc}1 & 2 & 3 & 4 & 5 & 6 & \begin{array}{c}7 \\ \text { strongly } \\ \text { agree } \\ \text { disagree }\end{array}\end{array}$

15. In which age group do you belong?

$$
\text { 18-20 21-23 24-26 27-29 } 30 \text { \& up }
$$

16. In to which student rank do you fall?

$$
\text { Freshman Sophomore Junior Senior Graduate }
$$

17. Of what ethnicity do you consider yourself?

$$
\text { Caucasian African American Asian Latino Other }
$$




\section{Appendix F, Actual Experiment}

\section{Please circle your answer to the following questions. Please choose only one answer to each question. Please answer the questions honestly and in numeric order.}

1. Are you a male between the ages of 18-35?

Yes No

*If no, you do not meet the age requirement for this experiment. Thank you for your participation; there is no need to continue this survey.

2. Does testicular cancer affect males your age?
Yes
No
Don’t Know

3. Have you ever performed a testicular self-examination (examined your testicles for abnormalities, lumps, or swelling)?
Yes
No
Don't Know

4. Have you personally ever known anyone who had/has testicular cancer?
Yes
No
Don't Know

5. If you answered yes to the previous question, what was the nature of your acquaintance with the person having testicular cancer?

Brother Father Friend Cousin Son Uncle Other 
On a scale of 1 to 7 , with 1 indicating strong disagreement and 7 indicating strong agreement, circle a number to represent how much you agree or disagree with the following statements:

6. Developing testicular cancer would be one of the worst things that could happen to me.

$\begin{array}{ccccccc}1 & 2 & 3 & 4 & 5 & 6 & \begin{array}{c}7 \\ \text { strongly } \\ \text { strongly } \\ \text { disagree }\end{array}\end{array}$

7. The negative aspects of testicular cancer feel serious to me.

$\begin{array}{ccccccc}1 & 2 & 3 & 4 & 5 & 6 & 7 \\ \begin{array}{c}\text { strongly } \\ \text { disagree }\end{array} & & & & & & \begin{array}{c}\text { strongly } \\ \text { agree }\end{array}\end{array}$

8. It is likely that testicular cancer will affect me.

$\begin{array}{ccccccc}1 & 2 & 3 & 4 & 5 & 6 & \begin{array}{c}7 \\ \text { strongly } \\ \text { agree } \\ \text { disagree }\end{array}\end{array}$

9. I already perform testicular self-examinations.

$\begin{array}{ccccccc}1 & 2 & 3 & 4 & 5 & 6 & \begin{array}{c}7 \\ \text { strongly } \\ \text { agree } \\ \text { disagree }\end{array}\end{array}$

10. I intend to perform TSE regularly in the next 6 months.

$\begin{array}{ccccccc}1 & 2 & 3 & 4 & 5 & 6 & \begin{array}{c}7 \\ \text { strongly } \\ \text { strongly } \\ \text { disagree }\end{array}\end{array}$

11. It is likely that I will perform a testicular self-examination TSE at least once in the next 6 months.

$\begin{array}{ccccccc}1 & 2 & 3 & 4 & 5 & 6 & \begin{array}{c}7 \\ \text { strongly } \\ \text { agree } \\ \text { disagree }\end{array}\end{array}$


12. I plan to perform TSE regularly (once a month) in the next 6 months.

$\begin{array}{ccccccc}1 & 2 & 3 & 4 & 5 & 6 & \begin{array}{c}7 \\ \text { strongly } \\ \text { agree } \\ \text { disagree }\end{array}\end{array}$

\section{Please read carefully the following message}




\section{(Fear message)}

\section{Please read carefully the following message}

\section{American Cancer Society wants you to know....}

You are in the prime age group for developing testicular cancer. It is the most common cancer and a leading cause of death for males your age. A simple testicular self-examination is encouraged to notice changes or discomfort in the scrotal area. A cancerous lump is most often found by performing a testicular self-examination. Remember, early detection will lessen your chance of death!

The Testicular Cancer Resource Center (TCRC.com) recommends following these steps every month:

- Stand in front of a mirror. Check for any swelling on the scrotal skin.

- Examine each testicle with both hands. Place the index and middle fingers under the testicle with the thumbs placed on top. Roll the testicle gently between the thumbs and fingers -- you shouldn't feel any pain when doing the exam.

- Find the epididymis, the soft, tubelike structure behind the testicle that collects and carries sperm. If you are familiar with this structure, you won't mistake it for a suspicious lump. Cancerous lumps usually are found on the sides of the testicle but can also show up on the front.

- If you find a lump on your testicle, see a doctor, preferably a urologist, right away. If it is testicular cancer, it will spread if it is not stopped by treatment. Waiting and hoping will not fix anything. Get any lumps checked by a doctor.

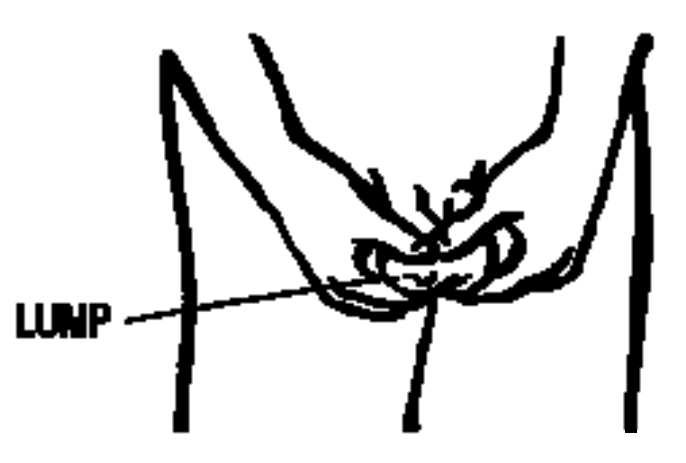

Your life could depend on it. 


\section{(Informative message)}

\section{Please read carefully the following message}

\section{American Cancer Society wants you to know....}

Testicular cancer is the most common cancer found in men between the ages of 15 and 35. Testicular cancer usually presents itself as a painless lump in one or both testes. When found early, testicular cancer holds a $96 \%$ survival rate. A simple testicular self-examination is encouraged to notice changes or discomfort in the scrotal area. If you find a lump or area of concern on the scrotum, a doctor should be notified immediately.

The Testicular Cancer Resource Center (TCRC.com) recommends following these steps every month:

- Stand in front of a mirror. Check for any swelling on the scrotal skin.

- Examine each testicle with both hands. Place the index and middle fingers under the testicle with the thumbs placed on top. Roll the testicle gently between the thumbs and fingers -- you shouldn't feel any pain when doing the exam.

- Find the epididymis, the soft, tubelike structure behind the testicle that collects and carries sperm. If you are familiar with this structure, you won't mistake it for a suspicious lump. Cancerous lumps usually are found on the sides of the testicle but can also show up on the front.

- If you find a lump on your testicle, see a doctor, preferably an urologist. The abnormality may not be cancer; it may just be an infection. When in doubt, get it checked out - if only for peace of mind.

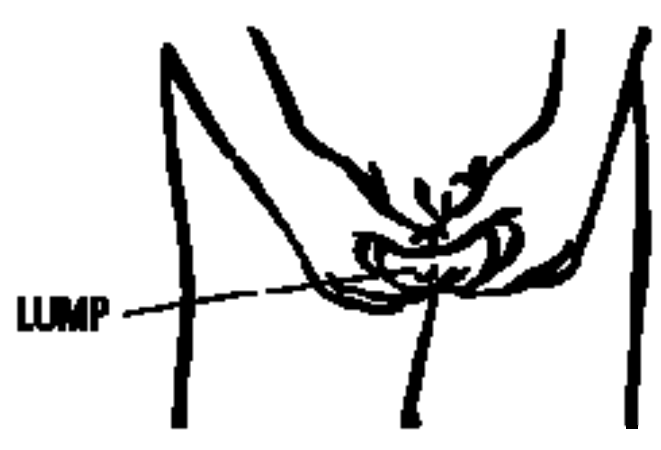


On a scale of 1 to 7 , with 1 indicating strong disagreement and 7 indicating strong agreement, circle a number to represent how much you agree or disagree with the following statements:

1. Developing testicular cancer would be one of the worst things that could happen to me.

$\begin{array}{ccccccc}1 & 2 & 3 & 4 & 5 & 6 & 7 \\ \begin{array}{c}\text { strongly } \\ \text { disagree }\end{array} & & & & & & \\ \text { strongly } \\ \text { agree }\end{array}$

2. The negative aspects of testicular cancer feel serious to me.

$\begin{array}{ccccccc}1 & 2 & 3 & 4 & 5 & 6 & \begin{array}{c}7 \\ \text { strongly } \\ \text { agree } \\ \text { disagree }\end{array}\end{array}$

3. It is likely that testicular cancer will affect me.

$\begin{array}{ccccccc}1 & 2 & 3 & 4 & 5 & 6 & \begin{array}{c}7 \\ \text { strongly } \\ \text { agree } \\ \text { disagree }\end{array}\end{array}$

4. I intend to perform TSE regularly in the next 6 months.

$\begin{array}{ccccccc}1 & 2 & 3 & 4 & 5 & 6 & \begin{array}{c}7 \\ \text { strongly } \\ \text { agree } \\ \text { disagree }\end{array}\end{array}$

5. It is likely that I will perform a testicular self-examination TSE at least once in the next 6 months.

$\begin{array}{ccccccc}1 & 2 & 3 & 4 & 5 & 6 & \begin{array}{c}7 \\ \text { strongly } \\ \text { agree } \\ \text { disagree }\end{array}\end{array}$

6. I plan to perform TSE regularly (once a month) in the next 6 months.

$\begin{array}{ccccccc}1 & 2 & 3 & 4 & 5 & 6 & \begin{array}{c}7 \\ \text { strongly } \\ \text { agree } \\ \text { disagree }\end{array}\end{array}$


7. The message I read made me feel fearful of testicular cancer.

$\begin{array}{ccccccc}1 & 2 & 3 & 4 & 5 & 6 & 7 \\ \begin{array}{c}\text { strongly } \\ \text { disagree }\end{array} & & & & & & \\ \text { strongly } \\ \text { agree }\end{array}$

8. The message I read makes me feel fearful about testicular cancer affecting me.

$\begin{array}{ccccccc}1 & 2 & 3 & 4 & 5 & 6 & \begin{array}{c}7 \\ \text { strongly } \\ \text { agree } \\ \text { disagree }\end{array}\end{array}$

9. In which age group do you belong?

$$
\text { 18-20 21-23 24-26 27-29 } 30 \text { \& up }
$$

10. In to which student rank do you fall?

Freshman Sophomore Junior Senior Graduate

11. Of what ethnicity do you consider yourself?

Caucasian African American Asian Latino Other 